УДК 556.531.4:550.84.094

\title{
ЭКСПЕРИМЕНТ ПО ОЦЕНКЕ САМООЧИЩЕНИЯ ОБСКОГО БОЛОТА (ЗАПАДНАЯ СИБИРЬ, ТОМСКАЯ ОБЛАСТЬ)
}

\author{
Савичев Олег Геннадьевич ${ }^{1}$, \\ OSavichev@mail.ru \\ Гусева Наталья Владимировна ${ }^{1}$, \\ guseva24@yandex.ru
}

Хващевская Альбина Анатольевна1,
Garibova@yandex.ru

Иванов Андрей Юрьевич 1 , IvanovAYu@tpu.ru

Ян Хэн ${ }^{1}$, 13698754927@163.com

Чжоу Дань', 929177582@qq.com

1 Национальный исследовательский Томский политехнический университет, Россия, 634050, г. Томск, пр. Ленина, 30.

\begin{abstract}
Актуальность. Равнинная территория Западной Сибири характеризуется очень высокой заболоченностью. Вследствие этого хозяйственная деятельность часто проводится на болотах и заболоченных землях, что определяет необходимость изучения самоочищения болотной среды для снижения негативного антропогенного воздействия на окружающую среду и оптимизации хозяйственной деятельности.

Цель: экспериментальное изучение условий распространения в болотной среде загрязняющих веществ и самоочищения евтрофрной болотной экосистемы.

Методы: полевой эксперимент, методы определения химического состава болотных вод и водных вытяжек из торфов и минеральных отложений, статистические методы.

Результаты и выводы. 18 марта 2021 г. на Обском болоте (юг Томской области) в районе с. Нащеково пробурено 5 скважин, отобраны пробы болотных вод в деятельном горизонте торфяной залежи и торфов через 0,25 м. Четыре скважины расположены в виде вершин квадрата со стороной 100 м. В середине квадрата на поверхности болота 19.03 .2021 г. выполнен вы-

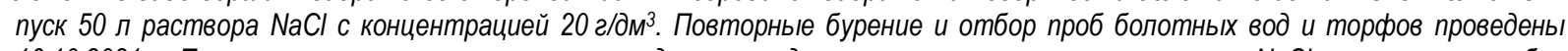
16.10.2021 г. Показано, что в течение этого периода непосредственно в месте выпуска раствора $\mathrm{NaCl}$ в интервале глубин

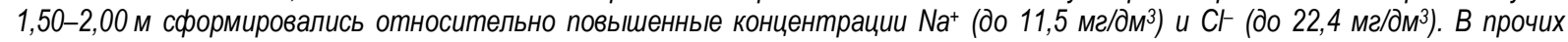
скважинах (на удалении около 70 м от выпуска) значимые изменения значений рH, удельной электропроводности EC, концентраций $\mathrm{Na}^{+}$и $\mathrm{Cl}^{-}$в болотных водах и водных вытяжках из торфов, связанные с выпуском раствора $\mathrm{NaCl}$, не выявлены, что свидетельствует о высокой способности болотной экосистемы к самоочищению.
\end{abstract}

\section{Ключевые слова:}

Самоочищение, химический состав, торфянная залежь, болотные воды, Обское болото, Западная Сибирь.

\section{Введение}

Западно-Сибирский территориальный комплекс в целом и Томская область в его составе в частности характеризуются двумя основными чертами - функционированием мощного нефтегазодобывающего комплекса и очень высокой заболоченностью [1-5]. Сочетание этих особенностей, в свою очередь, приводит к сильнейшему взаимовлиянию хозяйственной деятельности и заболоченности - болота определяют специфику проектов и условий эксплуатации месторождений углеводородов и объектов инфраструктуры, а хозяйственная деятельность приводит к изменениям параметров болотных процессов (формирования и эволюции болотных экосистем), причем эти изменения во многих случаях не сводятся к прямолинейному уничтожению болот. Напротив, строительство дорог в ряде случаев сопровождается переобводнением прилегающих участков и усилением их заболачива- ния, а сброс (систематический или аварийный) сточных вод или рекультивация - не к деградации болота, а к изменению его водно-минерального питания, что иногда сопровождается формированием весьма устойчивых болотных экосистем евтрофного типа.

Указанные выше обстоятельства определяют актуальность изучения способности болот региона к самовосстановлению в целом и к их самоочищению от загрязняющих веществ, поступающих со сточными водами, в частности. С учетом этого в Томском политехническом университете (ТПУ) в течение многих лет выполняются исследования, в процессе которых рассмотрены условия использования болот в составе природно-техногенных систем очистки стоков, анализируются пространственно-временные изменения гидрологических и геохимических условий функционирования болот и возможные изменения состояния болот при разработке месторождений осадочных же- 
лезных руд и сброса стоков на основе математического моделирования гидрогеохимических процессов. В том числе, с 2002 г. выполняются работы по изучению условий формирования химического состава болотных вод и торфов Обского болота, расположенного в левобережной части долины р. Оби (преимущественно на первой надпойменной террасе) на участке сел Нащеково (фоновый участок) и Мельниково (участок многолетнего сброса хозяйственно-бытовых сточных вод) в Томской области [6-8]. Ниже представлены результаты очередного этапа этих исследований, в рамках которого был проведен эксперимент по изучению условий распространения загрязняющих веществ в болотной среде и ее самоочищения в случае аварийного сброса сточных вод.

Основная цель рассматриваемого исследования экспериментальное изучение условий распространения в болотной среде загрязняющих веществ (после выпуска на поверхность болота 50 л раствора $\mathrm{NaCl}$ с концентрацией 20 г/дм³ ) и самоочищения евтрофной болотной экосистемы в результате смешения болотных, подземных и сточных вод. Задачи исследования: 1) уточнение химического состава болотных вод на фоновом и загрязненном участках; 2) сопоставление геохимических показателей болотных и подземных вод (потенциально и фактически гидравлически связанных); 3) проведение эксперимента по изменению химического состава болотных вод и водных вытяжек из торфов на участке $100 \times 100$ м в течение мартаоктября 2021 г.

\section{Объект и методика исследования}

Объект исследования - Обское евтрофное (низинное) болото общей длиной около 104 км, шириной 1,5-7,0 км и мощностью торфяной залежи в среднем около 3,2 м и максимумами до 5-6 м. Указанное болото расположено в левобережной части долины p. Оби, преимущественно на первой надпойменной террасе Оби. Торфа низинные, со степенью разложения 34 \% и зольностью 28-29 \% [6-10]. На границе первой надпойменной террасы в болото разгружаются подземные воды, в том числе напорные воды отложений палеогена и мела [11]. На участке у с. Мельниково в Обское болото [6, 7] в течение многих лет поступают хозяйственно-бытовые сточные воды.

18 марта 2021 г. на фоновом участке Обского болота у с. Нащеково было пробурено пять скважин (рис. 1), в которых отобраны пробы болотных вод из деятельного горизонта торфяной залежи, а затем пробы торфа и минеральных отложений поинтервально (через 0,25 м) по всей глубине торфяной залежи до минерального грунта включительно. Четыре скважины (H1: 56³0,905' с.ш., 84²1,571'в.д.; Н2: 56³0,864' с.ш., $84^{\circ} 1,504^{\prime}$ в.Д.; Н4: 56³0,822' с.ш.,

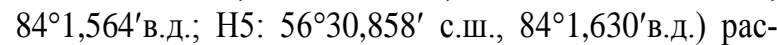
положены в вершинах квадрата со стороной 100 м, а пятая (Н3: 56³0,861' с.ш., 84²1,565'в.д.) - в его центре (рис. 1). После отбора проб воды и торфов 19 марта в 0,5 м от скважины Н3 на поверхность болота было вылито 50 л раствора $\mathrm{NaCl}\left(20\right.$ г/дм $\left.{ }^{3}\right) .16$ октября 2021 г. в этих же скважинах и в той же последовательности отобраны пробы болотной воды (из деятельного горизонта), торфа и минеральных отложений. Также 18.03.2021 г. и 16.10.2021 г. в трех километрах от скважин Н1-Н5 на Обском болоте в марте и октябре 2021 г. на окраине с. Нащеково были отобраны пробы подземной воды П (56³1,842' с.ш., $84^{\circ} 4,013^{\prime}$ в.д.), а 19.03.2021 г. в с. Мельниково вдоль дороги «Мельниково - Старая Шегарка» - две пробы болотных вод M1 (56³3,126' с.ш., 84º,384'в.д., в 0,70 км от суходола и 0,92 км от выпуска стоков по прямой) и М2 $\left(56^{\circ} 33,179^{\prime}\right.$ с.ш., $84^{\circ} 5,958^{\prime}$ в.д., в 0,25 км от суходола и 0,62 км от выпуска стоков) на загрязненном участке Обского болота. Отбор проб торфов, болотных и подземных вод выполнен с учетом требований [12-15].

В пробах болотных, подземных и сточных вод в аккредитованной гидрогеохимической лаборатории Томского политехнического университета (ТПУ) определялись значения $\mathrm{pH}$ (потенциометрический метод), удельная электропроводность $E C$ (кондуктометрический), бихроматная окисляемость $B O$ (флуориметрический), перманганатная окисляемость $P O$, валовые содержания $\mathrm{Ca}^{2+}, \mathrm{Mg}^{2+}, \mathrm{HCO}_{3}^{-}, \mathrm{Cl}^{-}, \mathrm{CO}_{2}$ (титриметрический), $\mathrm{SO}_{4}^{2-}$ (турбидиметрический), $\mathrm{NH}_{4}^{+}$, $\mathrm{NO}_{2}^{-}, \mathrm{NO}_{3}^{-}$(фотометрический), $\mathrm{Na}^{+}, \mathrm{K}^{+}$(пламенноэмиссионная спектрометрия), Fe и более 30 микроэлементов (масс-спектрометрический с индуктивносвязанной плазмой МС-ИСП с использованием массспектрометра NexION 300D). B пробах H2, H3, M1, M2 (отобранных 19.03.2021 г.) также определены содержания органических микропримесей [7].

В водных вытяжках из предварительно высушенных проб торфов и минеральных грунтов определялись значения $\mathrm{pH}$ (потенциометрический метод) и $E C$ (кондуктометрический), концентрации $\mathrm{Na}^{+}$(пламенно-эмиссионная спектрометрия) и $\mathrm{Cl}^{-}$(ионная хроматография). При этом пробоподготовка включала в себя доведение проб до воздушно-сухого состояния, растирание в фарфоровой ступке, перемешивание в круглодонной колбе в течение трех минут навески 50-100 г с добавлением деионизированной воды, центрифугирование в течение пяти минут. Более подробная информация о методиках пробоподготовки и методах анализа приведена в $[7,16]$.

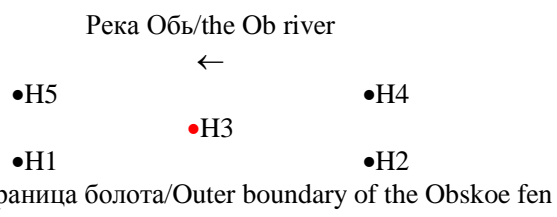

ис. 1. Схема расположения скважин на Обском боло те у с. Нашеково в левобережной части долины p. Обь при проведении эксперимента; «њ»направление течения в р. Обь и снижения высотных отметок Обского болота

Fig. 1. Boreholes layout on the Obskoe fen at Nashchekovo village in the left-bank part of the $\mathrm{Ob}$ river valley; "৬) is a direction of current in the $\mathrm{Ob}$ river and reductions in high-altitude marks of the Obskoe fen 
Сравнение данных проводилось путем вычисления и анализа относительного изменения величины $\delta(X)$ для значений $\mathrm{pH}, E C$, концентраций $\mathrm{Na}^{+}$и $\mathrm{Cl}^{-}$в каждом интервале глубин по уравнению (1), проверки с уровнем значимости $5 \%$ на однородность по дисперсии и среднему (в водных вытяжках из торфов) с использованием критериев Фишера $K_{F}(2)$ и Стьюдента $K_{S}(3)$, соответственно [17], а также критерия $K_{D}$, связанного с критерием Нэша-Сатклифа $K_{N S}[18]$ отношением (4):

$$
\begin{gathered}
\delta(X)=100 \frac{X_{i, t_{2}}-X_{i, t_{1}}}{X_{i, t_{1}}}, \\
K_{F}=\frac{\max \left(D_{1} ; D_{2}\right)}{\min \left(D_{1} ; D_{2}\right)}, \\
K_{S}=\frac{\left|A_{1}-A_{2}\right|}{\sqrt{N_{1} D_{1}+N_{2} D_{2}}} \sqrt{\frac{N_{1} N_{2}\left(N_{1}+N_{2}-2\right)}{N_{1}+N_{2}}}, \\
K_{D}=\sqrt{1-K_{N S}}=\sqrt{\frac{\sum\left(X_{i, t_{2}}-X_{i, t_{1}}\right)^{2}}{\sum\left(X_{i, t_{1}}-X_{a, t_{1}}\right)^{2}},}
\end{gathered}
$$

где $X_{i, t_{1}}$ и $X_{i, t_{2}}$ - значения показателя $X$, полученные в сроки $t_{1}(18.03 .2021)$ и $t_{2}(16.10 .2021)$ в скважине $i ; A_{1}$, $A_{2}, D_{1}, D_{2}$ - средние арифметические значения и дисперсии для двух выборок водных вытяжек из торфов объемами $N_{1}=N_{2}=N$ (для болотных вод $N=5$, для торфов и минеральных отложений значение $N$ соответствует количеству интервалов опробования в каждой из скважин).

В процессе анализа полученных данных также проводился корреляционный и регрессионный анализ с учетом требований [17]. В общем случае связи между сравниваемыми показателями принимались статистически значимыми (с уровнем значимости 5 \%) при условии, что коэффициенты корреляции $r$ по модулю больше 0,70 , квадрат корреляционного отношения $R^{2}$ более 0,36 , коэффициенты корреляции и регрессии больше удвоенной погрешности их определения. Расчеты выполнены в MS Excel.

\section{Результаты исследования и их обсуждение}

Болотные воды на фоновом участке у с. Нащеково 18 марта и 16 октября 2021 г. в целом характеризуются по классификации О.А. Алекина [19] как пресные с повышенной минерализацией, за исключением пробы, отобранной 18.03.2021 г. в скважине Н4. Болотные воды на загрязненном участке у с. Мельниково солоноватые, а подземные воды в с. Нащеково пресные с повышенной минерализацией с общим содержанием растворенных солей, близким к категории «солоноватые воды» (табл. 1). По химическому составу болотные воды гидрокарбонатные кальциевые, а подземные воды гидрокарбонатные натриевые. Болотные воды характеризуются очень высокими значениями бихроматной и перманганатной окисляемости - косвенных показателей содержания органических веществ, в составе которых на фоновом участке выявлены повышенные концентрации органических фосфатов. В болотных водах загрязненного участка за- фиксирован заметно более высокий уровень содержания фталатов, сложных эфиров, жирных кислот, спиртов алифатических (табл. 2), что согласуется как с ранее полученными данными на Обском болоте [7], так и с материалами других авторов [20-22].

В болотных водах обнаружены и очень высокие валовые концентрации $\mathrm{Fe}$, особенно в скважине $\mathrm{H} 2$, расположенной ближе к внешней границе болота и выше по уклону от скважины Н3 (табл. 1, рис. 1). На этом участке отсутствовали какие-либо сбросы сточных вод или размещение отходов, которые могли бы быть причиной повышения концентрация железа 16 октября в сравнении с пробой, отобранной 18 марта того же года. Поэтому, с учетом [23-26], более вероятной причиной является повышение концентрации продуктов трансформации органического вещества и образования коллоидных и взвешенных соединений металлов с фосфатами и органическими кислотами с учетом пространственной неоднородности влажности и вещественного состава торфов вследствие пространственно-временных изменений разгрузки подземных вод и отклика болотной экосистемы на их поступление.

Это предположение косвенно подтверждается наличием регрессионной зависимости между валовыми содержаниями $\mathrm{Fe}$ и $\mathrm{P}$ (рис. 2). Причем повышенные значения $B O$ и $P O$ и продуктов разложения органического вещества (например, Р) в общем случае не совпадают по времени и в пространстве (табл. 1), что свидетельствует о неравномерности соответствующих биогеохимических процессов как об одном из важных факторов формирования химического состава болотных вод и торфов.

В результате проведения эксперимента (выпуск 50 л раствора $\mathrm{NaCl}$ с концентрацией 20 г/дм ${ }^{3}$ в скважине H3) выявлено некоторое увеличение концентраций $\mathrm{Cl}^{-}$в болотных водах в деятельном горизонте непосредственно в месте выпуска, но заметное увеличение содержания $\mathrm{Na}^{+}$не зафиксировано. Относительное увеличение концентраций $\mathrm{Cl}^{-}$обнаружено также в скважине Н1 (рис. 3, табл. 1). Проверка выборок (из пяти проб в каждой) на однородность по среднему и дисперсии показала, что в октябре 2021 г., по сравнению с мартом того же года, произошло статистически значимое уменьшение удельной электропроводности (табл. 3), а также окисляемости и суммарного содержания растворенных солей. Последнее связано главным образом со снижением концентраций $\mathrm{HCO}_{3}^{-}$, причем одновременно выявлено увеличение концентраций растворенного $\mathrm{CO}_{2}$, что также свидетельствует о природном изменении биогеохимических процессов в болотной среде. Непосредственно по содержанию $\mathrm{Na}^{+}$и $\mathrm{Cl}^{-}$в болотных водах нарушения однородности не обнаружены (табл. 3).

Более существенные изменения (с марта по октябрь) отмечены для указанных выше элементов (а также величин $E C$ и рН) в водных вытяжках из торфов в четырех скважинах из пяти (H1, Н3, H4, Н5; табл. 3). При этом следует отметить, что в скважине $\mathrm{H} 3$, где проведен выпуск раствора $\mathrm{NaCl}$, заметное увеличение $\mathrm{Na}^{+}(153 \%)$ и $\mathrm{Cl}^{-}(365 \%)$ было зафикси- 
ровано в интервале глубин 1,50-1,75 м, в меньшей степени - до 2,00 м (табл. 4). Но в этой же скважине наблюдалось и снижение концентраций $\mathrm{Na}^{+}$и $\mathrm{Cl}^{-}$в нижней части торфяной залежи.

Таблица 1. Физико-химические показатели и химический состав подземных (П) и болотных вод на фоновом (H1-H5) и загрязненном (M1, M2) участках Обского болота

Table 1. Physical and chemical parameters and chemical composition of ground (П) and fen waters on background (H1H5) and polluted (M1, M2) sites of the Obskoe fen

\begin{tabular}{|c|c|c|c|c|c|c|c|c|c|c|c|c|c|c|c|}
\hline \multirow[b]{2}{*}{$\begin{array}{l}\text { Показа- } \\
\text { тель } \\
\text { Indicator }\end{array}$} & \multirow[b]{2}{*}{$\begin{array}{c}\text { Единицы } \\
\text { измерения } \\
\text { Units }\end{array}$} & \multicolumn{2}{|c|}{ H1 } & \multicolumn{2}{|c|}{$\mathrm{H} 2$} & \multicolumn{2}{|c|}{$\mathrm{H} 3$} & \multicolumn{2}{|c|}{$\mathrm{H} 4$} & \multicolumn{2}{|c|}{$\mathrm{H} 5$} & \multicolumn{2}{|c|}{$\Pi$} & \multirow{2}{*}{ 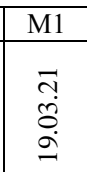 } & \multirow{2}{*}{$\begin{array}{l}\text { M2 } \\
\vec{\sim} \\
\tilde{o} \\
\stackrel{-}{\sigma}\end{array}$} \\
\hline & & $\begin{array}{l}\bar{N} \\
\tilde{o} \\
\infty \\
\infty\end{array}$ & $\begin{array}{l}\vec{\imath} \\
\stackrel{0}{0} \\
\stackrel{0}{0}\end{array}$ & $\begin{array}{l}\bar{त} \\
\tilde{O} \\
\infty \\
\infty\end{array}$ & $\begin{array}{l}\tilde{ָ} \\
\stackrel{0}{0} \\
\stackrel{0}{0}\end{array}$ & $\begin{array}{l}\bar{त} \\
\stackrel{0}{0} \\
\infty \\
\infty\end{array}$ & $\begin{array}{l}\vec{\imath} \\
\stackrel{0}{0} \\
\stackrel{0}{0}\end{array}$ & $\begin{array}{l}\bar{\sim} \\
\tilde{o} \\
\infty \\
\infty\end{array}$ & $\begin{array}{l}\vec{\jmath} \\
\stackrel{0}{0} \\
\stackrel{0}{0}\end{array}$ & $\begin{array}{l}\vec{n} \\
\tilde{o} \\
\infty \\
\infty\end{array}$ & $\begin{array}{l}\tilde{ָ} \\
\stackrel{0}{0} \\
\underline{0}\end{array}$ & $\begin{array}{l}\bar{ָ} \\
\tilde{O} \\
\infty \\
\infty\end{array}$ & $\begin{array}{l}\overrightarrow{\tilde{c}} \\
\stackrel{0}{0} \\
\underline{0}\end{array}$ & & \\
\hline$h_{p}$ & $\mathrm{M} / \mathrm{m}$ & \multicolumn{2}{|c|}{5,00} & \multicolumn{2}{|c|}{5,75} & \multicolumn{2}{|c|}{4,50} & \multicolumn{2}{|c|}{4,75} & \multicolumn{2}{|c|}{5,00} & \multicolumn{2}{|c|}{-} & 4,00 & 5,00 \\
\hline$h_{p I}$ & $\begin{array}{c}\text { то же } \\
\text { the same }\end{array}$ & 0,15 & 0,00 & 0,10 & 0,00 & 0,25 & 0,00 & 0,25 & 0,00 & 0,12 & 0,00 & \multicolumn{2}{|c|}{ - } & 0,00 & 0,00 \\
\hline$E C$ & $\begin{array}{c}\mathrm{MKCM} / \mathrm{cm} \\
\mu \mathrm{S} / \mathrm{cm}\end{array}$ & 508 & 458 & 654 & 520 & 647 & 491 & 1318 & 478 & 630 & 452 & 1204 & 892 & 1792 & 1914 \\
\hline $\mathrm{pH}$ & $\begin{array}{c}\text { ед. } \mathrm{pH} \\
\text { unit of } \mathrm{pH}\end{array}$ & 7,57 & 7,24 & 7,48 & 6,84 & 7,1 & 7,17 & 7,54 & 7,21 & 7,31 & 7,43 & 7,5 & 7,08 & 7,82 & 7,57 \\
\hline$B O$ & $\mathrm{M \Gamma O} /$ дм $^{3}$ & 135,0 & 23,0 & 125,0 & 57,0 & 600,0 & 70,0 & 213,0 & 58,0 & 152,0 & 54,0 & 8,9 & 57,0 & 136,0 & 423,0 \\
\hline$P O$ & $\mathrm{mgO} / \mathrm{dm}^{3}$ & 47,6 & 5,8 & 39,2 & 9,3 & 69,6 & 7,8 & 40,8 & 2,0 & 42,8 & 6,2 & 1,5 & 2,3 & 44,1 & 58,7 \\
\hline $\mathrm{CO}_{2}$ & $\begin{array}{l}\mathrm{M \Gamma} / \text { дм }^{3} \\
\mathrm{mg} / \mathrm{dm}^{3}\end{array}$ & 1,9 & 10,6 & 2,6 & 22,9 & 3,5 & 17,6 & 2,6 & 12,3 & 3,5 & 5,3 & 2,6 & 17,6 & 1,9 & 4,4 \\
\hline$\Sigma_{\mathrm{mi}}$ & $\begin{array}{c}\text { то же } \\
\text { the same }\end{array}$ & 461,1 & 496,4 & 591,1 & 553,7 & 660,4 & 549,0 & 1031,9 & 527,7 & 649,0 & 486,4 & 946,8 & 890,0 & 1253,4 & 1400,8 \\
\hline $\mathrm{Ca}^{2+}$ & $-/ /-$ & 96,0 & 84,0 & 132,0 & 118,0 & 119,0 & 88,0 & 183,0 & 100,0 & 125,0 & 92,0 & 90,0 & 96,0 & 160,0 & 160,0 \\
\hline $\mathrm{Mg}^{2+}$ & $-1 /-$ & 6,0 & 23,2 & 4,0 & 13,4 & 24,0 & 47,6 & 42,0 & 17,1 & 18,3 & 23,2 & 24,4 & 31,7 & 30,5 & 24,4 \\
\hline $\mathrm{Na}^{+}$ & $-1 /-$ & 8,9 & 6,3 & 6,4 & 6,2 & 8,2 & 8,1 & 12,5 & 8,0 & 8,6 & 7,3 & 140,0 & 115,0 & 152,0 & 177,0 \\
\hline $\mathrm{K}^{+}$ & $-1 /-$ & 1,8 & 1,3 & 1,0 & 2,8 & 3,0 & 2,0 & 5,0 & 4,8 & 0,9 & 0,5 & 3,0 & 2,2 & 14,2 & 14,9 \\
\hline $\mathrm{HCO}_{3}{ }^{-}$ & $-1 /-$ & 346 & 376 & 439 & 410 & 498 & 386 & 756 & 395 & 492 & 361 & 595 & 576 & 659 & 844 \\
\hline $\mathrm{SO}_{4}{ }^{2-}$ & $-/ /-$ & 1,4 & 4,2 & 3,3 & $<1$ & 2,6 & 0,7 & 14,4 & $<1$ & 3,2 & 1,4 & 2,4 & 3,6 & 8,7 & 13,5 \\
\hline $\mathrm{Cl}^{-}$ & $-/ /-$ & 1,0 & 1,5 & 5,4 & 3,3 & 5,6 & 16,6 & 19,0 & 2,8 & 1,0 & 1,0 & 92,0 & 65,5 & 229,0 & 167,0 \\
\hline $\mathrm{NO}_{3}^{-}$ & $-1 /-$ & 0,22 & 0,27 & 0,17 & 0,23 & 0,19 & 0,17 & 0,27 & 0,23 & 0,42 & 0,18 & 1,85 & 2,43 & 0,13 & 0,13 \\
\hline $\mathrm{NO}_{2}^{-}$ & $-I /-$ & $<0,02$ & $<0,02$ & $<0,02$ & $<0,02$ & $<0,02$ & $<0,02$ & $<0,02$ & $<0,02$ & $<0,02$ & $<0,02$ & $<0,02$ & $<0,02$ & $<0,02$ & $<0,02$ \\
\hline $\mathrm{NH}_{4}^{+}$ & $-/ /-$ & 0,11 & 0,15 & 0,18 & 0,75 & 0,32 & 0,21 & 0,46 & 0,34 & 0,29 & 0,11 & 0,11 & 0,06 & 0,32 & 9,60 \\
\hline $\mathrm{P}$ & $-1 /-$ & 0,15 & 0,13 & 0,16 & 5,27 & 0,78 & 2,02 & 2,36 & 1,46 & 0,75 & 0,33 & 0,05 & 0,05 & 0,94 & 10,40 \\
\hline $\mathrm{Si}$ & $-/ /-$ & 6,8 & 6,1 & 7,9 & 8,2 & 9,9 & 6,7 & 19,0 & 5,5 & 9,6 & 5,1 & 13,2 & 14,4 & 16,5 & 15,0 \\
\hline $\mathrm{Fe}$ & $-I /-$ & 1,81 & 1,53 & 3,79 & 46,69 & 10,98 & 10,38 & 8,98 & 19,79 & 8,52 & 4,65 & 0,07 & 0,08 & 11,30 & 15,80 \\
\hline $\mathrm{Li}$ & $\begin{array}{l}\text { мкг/дм }{ }^{3} \\
\mathrm{mkg} / \mathrm{dm}^{3}\end{array}$ & 3,77 & 4,95 & 4,97 & 8,15 & 5,11 & 5,98 & 6,94 & 6,33 & 4,37 & 6,08 & 3,76 & 4,57 & 9,26 & 6,37 \\
\hline $\mathrm{Al}$ & $\begin{array}{c}\text { то же } \\
\text { the same }\end{array}$ & 3,5 & 6,2 & 11,3 & 363,5 & 19,4 & 9,0 & 0,9 & 50,3 & 2,5 & 1,8 & 0,1 & 0,7 & 428,0 & 41,1 \\
\hline $\mathrm{Ti}$ & $-\| /-$ & 1,03 & 1,13 & 1,68 & 27,08 & 3,54 & 2,92 & 3,27 & 4,34 & 2,25 & 1,01 & 1,15 & 1,19 & 15,61 & 13,09 \\
\hline $\mathrm{V}$ & $-1 /-$ & 0,04 & 0,10 & 0,09 & 3,13 & 0,16 & 0,14 & 0,02 & 0,55 & 0,01 & 0,03 & 0,10 & 0,09 & 4,96 & 0,51 \\
\hline $\mathrm{Cr}$ & $-1 /-$ & 1,72 & 1,66 & 2,44 & 6,56 & 2,92 & 1,65 & 3,47 & 2,10 & 2,46 & 1,49 & 3,47 & 2,75 & 3,63 & 3,74 \\
\hline $\mathrm{Mn}$ & $-1 /-$ & 108 & 129 & 1345 & 3967 & 1607 & 174 & 1451 & 847 & 1358 & 166 & 7 & 3 & 983 & 1166 \\
\hline Co & $-/ /-$ & 0,135 & 0,162 & 0,737 & 2,334 & 0,814 & 0,181 & 0,441 & 0,398 & 0,555 & \begin{tabular}{|l|}
0,103 \\
\end{tabular} & 0,109 & 0,087 & \begin{tabular}{|l|}
1,947 \\
\end{tabular} & 0,616 \\
\hline $\mathrm{Ni}$ & $-1 /-$ & 0,17 & 0,106 & 0,93 & 4,127 & 0,27 & 0,370 & 0,21 & \begin{tabular}{|l|l|}
0,635 \\
\end{tabular} & 0,17 & \begin{tabular}{|l|}
0,106 \\
\end{tabular} & 0,03 & \begin{tabular}{|l|l|}
0,025 \\
\end{tabular} & 2,74 & 2,03 \\
\hline $\mathrm{Cu}$ & $-1 /-$ & 0,11 & 0,257 & 2,21 & 5,350 & 0,17 & 0,318 & 0,31 & 1,270 & 0,07 & 0,067 & 0,18 & 0,304 & 4,86 & 3,54 \\
\hline $\mathrm{Zn}$ & $-1 /-$ & 1,73 & 3,542 & 10,19 & 74,036 & 5,11 & 5,433 & 4,39 & 19,809 & 1,13 & 1,352 & 3,20 & 2,622 & 16,26 & 16,90 \\
\hline $\mathrm{Y}$ & $-\| / /-$ & 0,015 & 0,026 & 0,030 & 1,383 & 0,051 & 0,051 & 0,006 & \begin{tabular}{|l|}
0,215 \\
\end{tabular} & 0,006 & 0,005 & 0,005 & 0,008 & 1,665 & 0,145 \\
\hline $\mathrm{Zr}$ & $-1 /-$ & 0,101 & 0,030 & 0,088 & 0,237 & 0,080 & 0,017 & 0,056 & \begin{tabular}{|l|}
0,037 \\
\end{tabular} & 0,097 & 0,010 & 0,048 & 0,025 & 0,309 & 0,105 \\
\hline $\mathrm{Ba}$ & $-/ /-$ & 74,52 & 102,41 & 114,27 & 917,39 & 159,19 & 405,54 & 195,20 & 417,96 & 135,92 & 126,28 & 416,68 & 389,73 & 231,06 & 331,94 \\
\hline $\mathrm{La}$ & $-1 /-$ & 0,0082 & 0,0261 & 0,0331 & 1,3995 & 0,0720 & 0,0416 & 0,0023 & \begin{tabular}{|l|l|}
0,1855 \\
\end{tabular} & 0,0068 & 0,0003 & 0,0003 & 0,0003 & \begin{tabular}{|l|}
1,7368 \\
\end{tabular} & 0,1814 \\
\hline $\mathrm{Ce}$ & $-1 /-$ & 0,0228 & 0,0477 & 0,0787 & 3,0219 & 0,1518 & 0,0753 & 0,0115 & 0,4300 & 0,0177 & 0,0003 & 0,0003 & 0,0058 & 3,8923 & 0,3576 \\
\hline Sm & $-1 /-$ & 0,0003 & 0,0211 & 0,0003 & 0,2873 & 0,0140 & 0,0429 & 0,0003 & 0,0257 & 0,0003 & 0,0093 & 0,0003 & 0,0003 & 0,4023 & 0,0457 \\
\hline $\mathrm{Eu}$ & $-1 /-$ & 0,0111 & 0,0062 & 0,0092 & 0,1084 & 0,0272 & 0,0268 & 0,0226 & 0,0402 & 0,0196 & 0,0122 & 0,0517 & 0,0389 & 0,1158 & 0,0579 \\
\hline Dy & $-1 /-$ & 0,0007 & \begin{tabular}{|l|}
0,0003 \\
\end{tabular} & 0,0062 & 0,1983 & 0,0034 & 0,0065 & 0,0003 & 0,0367 & 0,0003 & 0,0003 & 0,0003 & 0,0003 & \begin{tabular}{|l|}
0,3129 \\
\end{tabular} & 0,0251 \\
\hline $\mathrm{Yb}$ & $-1 /-$ & 0,0003 & 0,0003 & 0,0003 & 0,0703 & 0,0003 & 0,0003 & 0,0003 & 0,0039 & 0,0003 & 0,0003 & 0,0003 & 0,0003 & \begin{tabular}{|l|}
0,1277 \\
\end{tabular} & 0,0018 \\
\hline $\mathrm{Bi}$ & $-/ /-$ & 0,002 & 0,002 & 0,002 & 0,012 & 0,002 & 0,002 & \begin{tabular}{|l|l|}
0,002 \\
\end{tabular} & $\mid 0,010$ & \begin{tabular}{|l|l|}
0,002 \\
\end{tabular} & 0,002 & 0,006 & \begin{tabular}{|l|}
0,002 \\
\end{tabular} & \begin{tabular}{|l|}
0,002 \\
\end{tabular} & \begin{tabular}{|l|l|}
0,002 \\
\end{tabular} \\
\hline
\end{tabular}

Примечание: $h_{p}$ - глубина торфяной залежи; $h_{p I}$ - толщина мерзлого слоя торфяной залежи; ЕС - удельная электропроводность; ВО и РО - бихроматная и перманганатная окисляемость; $\Sigma_{\text {mi }}-$ сумма главных ионов $\left(\mathrm{Ca}^{2+}, \mathrm{Mg}^{2+}\right.$, $\mathrm{Na}^{+}, \mathrm{K}^{+}, \mathrm{HCO}_{3}^{-}, \mathrm{CO}_{3}^{2-}, \mathrm{SO}_{4}^{2-}, \mathrm{Cl}$ ).

Note: $h_{p}$ is depth of a peat deposit; $h_{p I}$ is the thickness of a frozen layer of a peat deposit; EC is the specific electric conductivity; $\mathrm{BO}$ and $\mathrm{PO}$ are the bichromate and permanganate oxidizability; $\Sigma_{m i}$ is the sum of the main ions $\left(\mathrm{Ca}^{2+}, \mathrm{Mg}^{2+}, \mathrm{Na}^{+}, \mathrm{K}^{+}\right.$, $\mathrm{HCO}_{3}^{-}, \mathrm{CO}_{3}{ }^{2-}, \mathrm{SO}_{4}{ }^{2-}, \mathrm{Cl}^{-}$). 
Таблица 2. Концентрации органических микропримесей в болотных водах по состоянию на 19.03.2021 2., мкг/дм

Table 2. Concentration of organic substances in fen waters, $19.03 .2021, \mathrm{mkg} / \mathrm{dm}^{3}$

\begin{tabular}{|c|c|c|c|c|}
\hline \multirow{2}{*}{ Показатель/Parameter } & $\mathrm{H} 2$ & $\mathrm{H} 3$ & M1 & M2 \\
\hline & \multicolumn{4}{|c|}{18.03 .21} \\
\hline Фталаты/Phthalates & 1793 & 2319 & 4605 & 6155 \\
\hline Алканы/Alkanes & 112 & 201 & 666 & 197 \\
\hline Спирты алифатические/Aliphatic alcohols & 188 & 361 & 522 & 560 \\
\hline Фенолы/Phenols & 16 & 337 & 303 & $<1$ \\
\hline Сложные эфиры/Esters & 1036 & 1667 & 2579 & 2571 \\
\hline Неидентифицированные вещества/Unidentified substances & 41 & 25 & 77 & 132 \\
\hline Углеводороды, исключая алканы/Hydrocarbons excluding alkanes & 11 & 13 & 174 & 33 \\
\hline Ароматические соединения/Aromatic compounds & 6 & 20 & 96 & $<1$ \\
\hline Жирные кислоты/Fatty acids & 452 & 52 & 677 & 715 \\
\hline Терпеноиды/Terpenoids & 356 & 354 & 437 & 634 \\
\hline Стероиды/Steroids & 252 & 91 & 524 & 375 \\
\hline Алкалоиды/Alkaloids & $<1$ & 10 & $<1$ & $<1$ \\
\hline Органические фосфаты/Organic phosphates & 21 & 5450 & 40 & 120 \\
\hline Соединение, содержащие серу/Compounds containing sulfur & 4 & $<1$ & $<1$ & $<1$ \\
\hline Соединения, содержащие азот/Compounds containing nitrogen & 61 & $<1$ & $<1$ & 160 \\
\hline Итого/Total & 4350 & 5450 & 10700 & 11650 \\
\hline
\end{tabular}

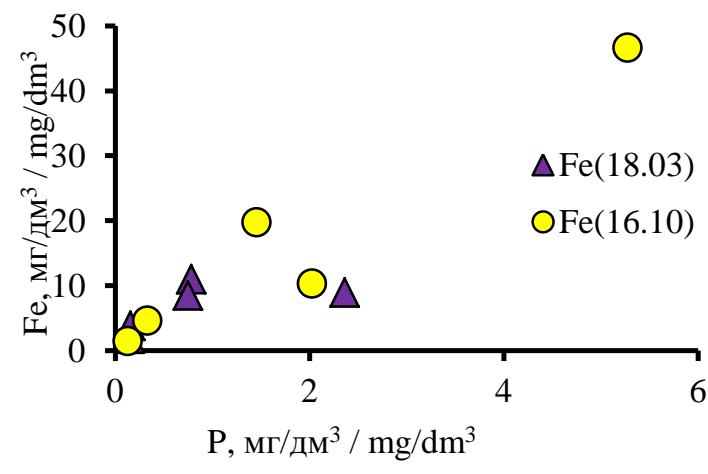

Pис. 2. Зависимость валовых концентраций $\mathrm{Fe}$ от содержания $P$ в болотных водах в деятельном горизонте торфяной залежи: $[\mathrm{Fe}]=(8,177 \pm 0,836) \cdot[\mathrm{P}]$; квадрат коррелячионного отношения $R^{2}=0,84$

Fig. 2. Dependence of Fe total concentration on $P$ content in fen waters in active horizon of a peat deposit: $[\mathrm{Fe}]=(8,177 \pm 0,836) \cdot[\mathrm{P}] ;$ a square of correlation relation $R^{2}=0,84$

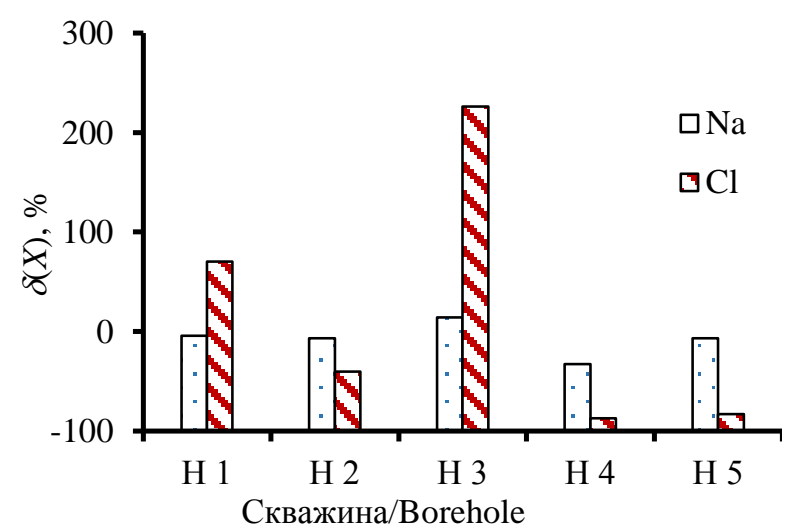

Pис. 3. Относительные изменения концентраций $\mathrm{Na}^{+} u$ $\mathrm{Cl}^{-}$в болотных водах в деятельном горизонте торфяной залежи Обского болота за период с 18.03.2021 до 16.10.2021

Fig. 3. Relative changes of $\mathrm{Na}^{+}$and $\mathrm{Cl}^{-}$concentration in fen waters in active horizon of peat deposit of the Obskoe fen from 18.03.2021 to 16.10.2021

Таблица 3. Соотночение фактических (индекс «f») и критических значений (индекс «5 \%» при уровне значимости $5 \%$ критериев Фишера $K_{F}(2)$ и Стьюдента $K_{S}(3)$ и значения критерия $K_{D}$ (4) для болотных вод и водных вытяжек из торфов Обского болота

Table 3. Ratio of actual (index « $f »)$ and critical values ( $45 \%$ index at a significance value of $5 \%$ ) of Fisher's $K_{F}(2)$ and Student's $K_{S}(3)$ criteria and values of criterion $K_{D}(4)$ for fen waters and water extracts from peats of the $O b$ skoe fen

\begin{tabular}{|c|c|c|c|c|c|c|c|c|c|c|c|c|}
\hline \multirow{2}{*}{$\begin{array}{c}\text { Скважина } \\
\text { Borehole }\end{array}$} & \multicolumn{3}{|c|}{$\mathrm{pH}$} & \multicolumn{3}{|c|}{$E C$} & \multicolumn{3}{|c|}{$\mathrm{Na}^{+}$} & \multicolumn{3}{|c|}{$\mathrm{Cl}^{-}$} \\
\hline & $K_{F(f)} / K_{F(5 \%)}$ & $K_{S(f)} / K_{S(5 \%)}$ & $K_{D}$ & $K_{F(f)} / K_{F(5 \%)}$ & $K_{S(f)} / K_{S(5 \%)}$ & $K_{D}$ & $K_{F(f)} / K_{F(5 \%)}$ & $K_{S(f)} / K_{S(5 \%)}$ & $K_{D}$ & $K_{F(f)} / K_{F(5 \%)}$ & $K_{S(f)} / K_{S(5 \%)}$ & $K_{D}$ \\
\hline \multicolumn{13}{|c|}{ Сравнение выборок по пяти скважинам в марте и октябре/Comparison of the data on five boreholes in March and October } \\
\hline $\mathrm{H} 1-\mathrm{H} 5$ & 0,12 & 0,66 & 1,84 & \begin{tabular}{l|l|l|l}
$\mathbf{1 4}, \mathbf{4 5}$ & \\
\end{tabular} & 0,73 & 1,23 & 0,61 & 0,63 & 1,09 & \begin{tabular}{l|l|l}
0,13 & \\
\end{tabular} & 0,12 & 1,19 \\
\hline \multicolumn{13}{|c|}{$\begin{array}{l}\text { Сравнение выборок по отдельным скважинам и в целом по пяти скважинам } \\
\text { Comparison of the data on separate boreholes and as a whole on five boreholes }\end{array}$} \\
\hline H1 & 0,46 & 1,60 & 1,40 & \begin{tabular}{l|}
0,91 \\
\end{tabular} & 0,96 & 0,81 & 3,34 & $\mathbf{1 , 0 7}$ & 2,97 & 0,41 & 2,67 & 2,02 \\
\hline $\mathrm{H} 2$ & 0,73 & 0,80 & 11,49 & 0,57 & 0,46 & 1,52 & 0,47 & 0,33 & 1,30 & 0,68 & 0,79 & 1,56 \\
\hline $\mathrm{H} 3$ & 0,95 & 1,79 & 1,80 & 2,02 & 1,02 & 0,93 & 0,62 & 0,57 & 1,12 & 0,71 & 0,35 & 1,30 \\
\hline $\mathrm{H} 4$ & 0,44 & 1,43 & 10,60 & 3,14 & 0,82 & 0,93 & 0,70 & 0,52 & 0,97 & 2,38 & $\mathbf{1 , 0 8}$ & 0,82 \\
\hline H5 & 0,91 & 0,16 & 1,44 & 1,22 & 0,81 & 1,00 & 1,16 & $\mathbf{1 , 5 3}$ & 1,03 & 2,02 & 1,43 & 1,05 \\
\hline $\mathrm{H} 1-\mathrm{H} 5$ & 1,26 & 0,23 & 7,08 & 2,28 & 1,67 & 0,90 & 1,04 & 0,23 & 1,35 & 1,41 & 2,04 & 1,14 \\
\hline
\end{tabular}

Примечание: случаи нарушения однородности выделены полужирным шрифтом.

Note: cases of infringement of uniformity are bolded. 
Таблица 4. Значения $\mathrm{pH}$, удельной электропроводности ЕC, концентрации $\mathrm{Na}^{+}$и $\mathrm{Cl}^{-}$в водных вытяжках из торфов и минеральных отложений Обского болота и их относительное изменение $\delta(X)$ (1) в течение 18.03.2021-16.10.2021

Table 4. Values of $\mathrm{pH}$, specific electric conductivity $\mathrm{EC}, \mathrm{Na}^{+}$and $\mathrm{Cl}^{-}$concentration in water extracts from peats and mineral sediments of the Obskoe fen and their relative change $\delta(X)(1)$ from 18.03.2021 to 16.10.2021

\begin{tabular}{|c|c|c|c|c|c|c|c|c|c|c|c|c|c|c|}
\hline \multirow{2}{*}{ 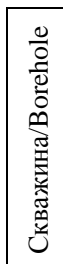 } & \multirow[b]{2}{*}{$\begin{array}{l}\text { 最莹 } \\
\text { 点号 }\end{array}$} & \multirow{2}{*}{ 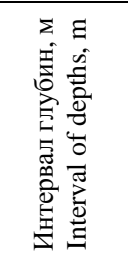 } & \multicolumn{2}{|c|}{$\begin{array}{l}\mathrm{pH}, \text { ед. } \mathrm{pH} \\
\text { units of } \mathrm{pH}\end{array}$} & \multirow[b]{2}{*}{$\begin{array}{c}\delta(\mathrm{pH}), \\
\%\end{array}$} & \multicolumn{2}{|c|}{$\begin{array}{c}\text { ЕС, мкC/см } \\
\mu \mathrm{S} / \mathrm{cm}\end{array}$} & \multirow[b]{2}{*}{$\begin{array}{c}\delta(\mathrm{EC}), \\
\%\end{array}$} & \multicolumn{2}{|c|}{$\begin{array}{c}\mathrm{Na}^{+}, \mathrm{M \Gamma} / \mathrm{дm}^{3} \\
\mathrm{mg} / \mathrm{dm}^{3}\end{array}$} & \multirow[b]{2}{*}{$\begin{array}{c}\delta\left(\mathrm{Na}^{+}\right), \\
\%\end{array}$} & \multicolumn{2}{|c|}{$\begin{array}{c}\mathrm{Cl}^{-}, \mathrm{Mr} / \mathrm{Am}^{3} \\
\mathrm{mg} / \mathrm{dm}^{3}\end{array}$} & \multirow[b]{2}{*}{$\delta\left(\mathrm{Cl}^{-}\right), \%$} \\
\hline & & & $\begin{array}{l}\bar{\sim} \\
\ddot{0} \\
\infty \\
\infty \\
0\end{array}$ & 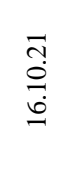 & & $\begin{array}{l}\vec{\sim} \\
\tilde{\sigma} \\
\infty \\
\infty\end{array}$ & $\begin{array}{l}\bar{ָ} \\
\stackrel{0}{0} \\
\varrho\end{array}$ & & $\begin{array}{l}\vec{\sim} \\
\tilde{O} \\
\infty \\
\infty\end{array}$ & 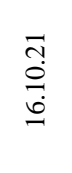 & & $\begin{array}{l}\vec{\sim} \\
\stackrel{\infty}{0} \\
\infty \\
\infty\end{array}$ & $\begin{array}{l}\overrightarrow{\widetilde{\sigma}} \\
\stackrel{0}{0} \\
\stackrel{0}{0}\end{array}$ & \\
\hline \multirow[t]{22}{*}{ H1 } & $\mathrm{T} / \mathrm{p}$ & $0,00-0,25$ & 7,87 & 7,74 & $-1,7$ & 152 & 125 & $-17,8$ & 8,1 & 11,2 & 37,6 & 7,8 & 2,8 & $-64,3$ \\
\hline & $\mathrm{T} / \mathrm{p}$ & $0,25-0,50$ & 7,67 & 7,50 & $-2,2$ & 102 & 113 & 11,0 & 7,6 & 7,6 & 0,1 & 8,4 & 2,1 & $-74,6$ \\
\hline & $\mathrm{T} / \mathrm{p}$ & $0,50-0,75$ & 7,80 & 8,09 & 3,7 & 89 & 87 & $-1,5$ & 4,8 & 11,8 & 146,9 & 7,8 & 5,0 & $-36,2$ \\
\hline & $\mathrm{T} / \mathrm{p}$ & $0,75-1,00$ & 7,81 & 7,85 & 0,5 & 89 & 72 & $-19,0$ & 3,8 & 2,9 & $-23,2$ & 6,5 & 1,1 & $-82,8$ \\
\hline & $\mathrm{T} / \mathrm{p}$ & $1,00-1,25$ & 7,88 & 7,56 & $-4,1$ & 86 & 79 & $-8,0$ & 4,0 & 7,6 & 88,1 & 4,7 & 1,0 & $-78,5$ \\
\hline & $\mathrm{T} / \mathrm{p}$ & $1,25-1,50$ & 7,80 & 7,58 & $-2,8$ & 91 & 83 & $-9,1$ & 4,0 & 4,9 & 22,4 & 5,2 & 1,1 & $-78,3$ \\
\hline & $\mathrm{T} / \mathrm{p}$ & $1,50-1,75$ & 7,92 & 7,40 & $-6,6$ & 86 & 82 & $-4,3$ & 3,7 & 4,3 & 17,0 & 4,4 & 1,0 & $-76,9$ \\
\hline & $\mathrm{T} / \mathrm{p}$ & $1,75-2,00$ & 8,28 & 7,60 & $-8,2$ & 84 & 90 & 6,5 & 5,2 & 3,5 & $-33,5$ & 6,5 & 1,5 & $-77,5$ \\
\hline & $\mathrm{T} / \mathrm{p}$ & $2,00-2,25$ & 8,23 & 7,89 & $-4,1$ & 96 & 84 & $-13,3$ & 2,7 & 3,1 & 13,3 & 3,7 & 0,9 & $-75,7$ \\
\hline & $\mathrm{T} / \mathrm{p}$ & $2,25-2,50$ & 8,32 & 7,88 & $-5,3$ & 88 & 86 & $-2,6$ & 2,5 & 2,8 & 14,2 & 3,7 & 0,3 & $-90,9$ \\
\hline & $\mathrm{T} / \mathrm{p}$ & $2,50-2,75$ & 8,34 & 8,15 & $-2,3$ & 82 & 75 & $-8,4$ & 2,6 & 3,9 & 51,6 & 4,9 & 1,5 & $-70,0$ \\
\hline & $\mathrm{T} / \mathrm{p}$ & $2,75-3,00$ & 8,34 & 8,04 & $-3,6$ & 78 & 74 & $-5,5$ & 2,5 & 4,5 & 82,5 & 3,3 & 1,1 & $-65,5$ \\
\hline & $\mathrm{T} / \mathrm{p}$ & $3,00-3,25$ & 8,26 & 8,01 & $-3,0$ & 88 & 70 & $-20,5$ & 3,2 & 20,2 & 537,2 & 3,4 & 0,8 & $-75,0$ \\
\hline & $\mathrm{T} / \mathrm{p}$ & $3,25-3,50$ & 8,28 & 8,02 & $-3,1$ & 89 & 69 & $-22,8$ & 2,5 & 3,8 & 55,7 & 3,1 & 1,0 & $-67,2$ \\
\hline & $\mathrm{T} / \mathrm{p}$ & $3,50-3,75$ & 8,26 & 8,07 & $-2,3$ & 99 & 75 & $-24,2$ & 3,5 & 3,3 & $-5,5$ & 3,8 & 1,2 & $-67,7$ \\
\hline & $\mathrm{T}($ (б)/p (w) & $3,75-4,00$ & 8,35 & 8,05 & $-3,6$ & 86 & 70 & $-18,5$ & 2,7 & 4,9 & 81,5 & 3,5 & 8,1 & 128,3 \\
\hline & $\mathrm{T} / \mathrm{p}$ & $4,00-4,25$ & 8,41 & 7,96 & $-5,4$ & 85 & 76 & $-10,7$ & 1,8 & 4,9 & 180,0 & 2,4 & 1,0 & $-57,0$ \\
\hline & $\mathrm{T} / \mathrm{p}$ & $4,25-4,50$ & 8,05 & 7,88 & $-2,1$ & 131 & 105 & $-20,2$ & 3,5 & 5,9 & 70,0 & 3,9 & 1,5 & $-62,2$ \\
\hline & ут/wp & $4,50-4,75$ & 8,01 & 7,91 & $-1,3$ & 157 & 110 & $-30,2$ & 8,7 & 16,2 & 85,6 & 5,2 & 1,3 & $-74,4$ \\
\hline & ут/wp & $4,75-5,00$ & 8,01 & 7,93 & $-1,0$ & 157 & 115 & $-26,9$ & 8,7 & 26,5 & 203,6 & 5,2 & 1,2 & $-77,1$ \\
\hline & OMO & $5,00-5,25$ & 8,39 & 7,88 & $-6,1$ & 87 & 93 & 6,6 & 2,3 & 15,4 & 562,5 & 2,7 & 1,2 & $-54,1$ \\
\hline & $\begin{array}{l}\text { Суглинок } \\
\text { Loam }\end{array}$ & $5,25-5,50$ & 8,26 & 7,83 & $-5,2$ & 104 & 72 & $-31,3$ & 2,1 & 4,2 & 105,8 & 2,6 & 1,3 & $-50,0$ \\
\hline $\mathrm{H} 2$ & $\mathrm{~T} / \mathrm{p}$ & $0,00-0,25$ & 7,94 & 7,83 & $-1,4$ & 123 & 129 & 5,0 & 6,0 & 4,5 & $-25,3$ & 2,6 & 6,0 & 132,6 \\
\hline & $\mathrm{T} / \mathrm{p}$ & $0,25-0,50$ & 7,99 & 8,04 & 0,6 & 184 & 83 & $-54,9$ & 7,1 & 4,5 & $-36,0$ & 10,1 & 1,6 & $-84,5$ \\
\hline & $\mathrm{T} / \mathrm{p}$ & $0,50-0,75$ & 8,06 & 7,99 & $-0,9$ & 130 & 88 & $-32,2$ & 2,9 & 3,7 & 29,2 & 6,5 & 8,7 & 33,5 \\
\hline & $\mathrm{T} / \mathrm{p}$ & $0,75-1,00$ & 8,18 & 7,96 & $-2,7$ & 109 & 71 & $-35,1$ & 1,8 & 3,0 & 65,4 & 2,4 & 1,5 & $-37,9$ \\
\hline & $\mathrm{T} / \mathrm{p}$ & $1,00-1,25$ & 8,35 & 8,04 & $-3,7$ & 82 & 71 & $-13,7$ & 1,9 & 2,2 & 15,4 & 2,4 & 1,0 & $-60,6$ \\
\hline & $\mathrm{T} / \mathrm{p}$ & $1,25-1,50$ & 8,40 & 7,98 & $-5,0$ & 79 & 63 & $-20,1$ & 2,1 & 2,6 & 23,0 & 4,1 & 0,7 & $-82,4$ \\
\hline & $\mathrm{T} / \mathrm{p}$ & $1,50-1,75$ & 8,34 & 8,04 & $-3,6$ & 81 & 78 & $-4,0$ & 2,2 & 4,8 & 116,8 & 3,3 & 0,9 & $-72,7$ \\
\hline & $\mathrm{T} / \mathrm{p}$ & $1,75-2,00$ & 8,32 & 7,93 & $-4,7$ & 81 & 73 & $-9,8$ & 1,5 & 2,8 & 81,6 & 2,0 & 1,0 & $-51,5$ \\
\hline & $\mathrm{T} / \mathrm{p}$ & $2,00-2,25$ & 8,34 & 8,03 & $-3,7$ & 82 & 75 & $-8,6$ & 1,9 & 2,2 & 18,5 & 1,9 & 0,8 & $-58,9$ \\
\hline & $\mathrm{T} / \mathrm{p}$ & $2,25-2,50$ & 8,33 & 7,94 & $-4,7$ & 77 & 74 & $-4,0$ & 1,7 & 2,3 & 37,5 & 1,7 & 0,9 & $-46,4$ \\
\hline & $\mathrm{T} / \mathrm{p}$ & $2,50-2,75$ & 8,22 & 8,19 & $-0,4$ & 89 & 82 & $-7,7$ & 2,5 & 1,8 & $-26,1$ & 3,0 & 1,8 & $-40,6$ \\
\hline & $\mathrm{T} / \mathrm{p}$ & $2,75-3,00$ & 8,18 & 8,43 & 3,1 & 101 & 90 & $-10,6$ & 1,5 & 1,4 & $-9,9$ & 2,7 & 2,7 & $-1,8$ \\
\hline & $\mathrm{T} / \mathrm{p}$ & $3,00-3,25$ & 8,06 & 8,36 & 3,7 & 114 & 107 & $-6,6$ & 1,4 & 2,3 & 56,9 & 2,4 & 1,9 & $-21,3$ \\
\hline & $\mathrm{T} / \mathrm{p}$ & $3,25-3,50$ & 8,08 & 8,16 & 1,0 & 109 & 140 & 28,5 & 4,0 & 2,1 & $-46,3$ & 4,1 & 2,4 & $-43,2$ \\
\hline & $\mathrm{T} / \mathrm{p}$ & $3,50-3,75$ & 8,09 & 8,10 & 0,1 & 121 & 135 & 11,3 & 3,5 & 3,6 & 0,6 & 3,9 & 2,6 & $-31,9$ \\
\hline & $\mathrm{T} / \mathrm{p}$ & $3,75-4,00$ & 8,18 & 8,53 & 4,3 & 110 & 83 & $-24,5$ & 2,1 & 2,7 & 31,3 & 3,4 & 8,3 & 148,2 \\
\hline & ут/wp & $4,00-4,25$ & 8,19 & 8,35 & 2,0 & 119 & 103 & $-13,9$ & 3,8 & 1,9 & $-48,5$ & 4,5 & 1,1 & $-76,3$ \\
\hline & $\mathrm{T} / \mathrm{p}$ & $4,25-4,50$ & 8,19 & 8,34 & 1,8 & 119 & 104 & $-12,9$ & 3,8 & 1,7 & $-56,0$ & 4,5 & 1,1 & $-75,0$ \\
\hline & Т (ч)/p (b) & $4,50-4,75$ & 8,03 & 7,98 & $-0,6$ & 140 & 147 & 4,6 & 2,2 & 1,5 & $-33,9$ & 3,0 & 4,3 & 42,4 \\
\hline & ут/wp & $4,75-5,00$ & 8,40 & 8,04 & $-4,3$ & 105 & 148 & 41,0 & 2,0 & 2,5 & 22,6 & 2,9 & 3,1 & 6,5 \\
\hline & ут/wp & $5,00-5,25$ & 8,40 & 8,09 & $-3,7$ & 105 & 150 & 42,6 & 2,0 & 3,5 & 72,6 & 2,9 & 1,9 & $-34,7$ \\
\hline & ут/wp & $5,25-5,50$ & 8,40 & 8,34 & $-0,7$ & 105 & 107 & 2,0 & 2,0 & 2,8 & 39,8 & 2,9 & 2,0 & $-30,6$ \\
\hline & ут/wp & $5,50-5,75$ & 8,40 & 8,44 & 0,5 & 105 & 103 & $-2,4$ & 2,0 & 8,3 & 314,9 & 2,9 & 1,3 & $-54,0$ \\
\hline $\mathrm{H} 3$ & $\mathrm{~T} / \mathrm{p}$ & $0,00-0,25$ & 8,00 & 7,85 & $-1,9$ & 300 & 175 & $-41,7$ & 8,3 & 9,3 & 12,5 & 10,5 & 8,1 & $-22,9$ \\
\hline & $\mathrm{T} / \mathrm{p}$ & $0,25-0,50$ & 8,08 & 8,19 & 1,4 & 345 & 184 & $-46,6$ & 19,8 & 6,8 & $-65,8$ & 14,6 & 10,8 & $-26,0$ \\
\hline & $\mathrm{T} / \mathrm{p}$ & $0,50-0,75$ & 8,02 & 8,26 & 3,0 & 216 & 131 & $-39,2$ & 8,4 & 3,6 & $-57,4$ & 6,3 & 3,1 & $-49,9$ \\
\hline & $\mathrm{T} / \mathrm{p}$ & $0,75-1,00$ & 8,11 & 8,28 & 2,1 & 147 & 108 & $-26,7$ & 4,0 & 2,5 & $-38,9$ & 3,0 & 2,2 & $-27,8$ \\
\hline & $\mathrm{T} / \mathrm{p}$ & $1,00-1,25$ & 8,12 & 8,34 & 2,7 & 148 & 109 & $-26,6$ & 4,4 & 3,4 & $-23,3$ & 2,9 & 3,2 & 11,5 \\
\hline & $\mathrm{T} / \mathrm{p}$ & $1,25-1,50$ & 8,15 & 8,36 & 2,6 & 133 & 132 & $-1,0$ & 4,5 & 10,8 & 142,2 & 3,1 & 14,4 & 358,6 \\
\hline & $\mathrm{T} / \mathrm{p}$ & $1,50-1,75$ & 8,30 & 8,26 & $-0,5$ & 107 & 176 & 64,2 & 4,6 & 11,5 & 152,7 & 4,8 & 22,4 & 364,7 \\
\hline & $\mathrm{T} / \mathrm{p}$ & $1,75-2,00$ & 8,19 & 8,24 & 0,6 & 133 & 124 & $-7,0$ & 4,6 & 5,3 & 15,6 & 3,8 & 12,2 & 225,3 \\
\hline & $\mathrm{T} / \mathrm{p}$ & $2,00-2,25$ & 8,13 & 8,26 & 1,6 & 141 & 117 & $-17,2$ & 5,5 & 4,1 & $-26,5$ & 6,9 & 6,6 & $-4,9$ \\
\hline & $\mathrm{T} / \mathrm{p}$ & $2,25-2,50$ & 8,18 & 8,38 & 2,4 & 134 & 98 & $-27,2$ & 3,9 & 3,1 & $-21,4$ & 3,5 & 4,1 & 16,1 \\
\hline & $\mathrm{T} / \mathrm{p}$ & $2,50-2,75$ & 8,15 & 8,29 & 1,7 & 136 & 115 & $-15,4$ & 4,0 & 5,9 & 47,6 & 2,9 & 5,4 & 85,6 \\
\hline & $\mathrm{T} / \mathrm{p}$ & $2,75-3,00$ & 8,10 & 8,24 & 1,7 & 154 & 127 & $-17,5$ & 4,6 & 4,2 & $-9,5$ & 4,0 & 6,7 & 68,3 \\
\hline
\end{tabular}


Известия Томского политехнического университета. Инжиниринг георесурсов. 2022. Т. 333. № 1. 73-84 Савичев О.Г. и др. Эксперимент по оценке самоочищения Обского болота (Западная Сибирь, Томская Область)

\begin{tabular}{|c|c|c|c|c|c|c|c|c|c|c|c|c|c|c|}
\hline \multirow{2}{*}{ 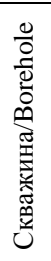 } & \multirow[b]{2}{*}{$\begin{array}{l}\text { 是总 } \\
\text { 点 }\end{array}$} & \multirow{2}{*}{ 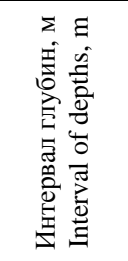 } & \multicolumn{2}{|c|}{$\begin{array}{l}\mathrm{pH}, \text { ед. } \mathrm{pH} \\
\text { units of } \mathrm{pH}\end{array}$} & \multirow[b]{2}{*}{$\underset{\%}{\delta(\mathrm{pH})}$} & \multicolumn{2}{|c|}{$\begin{array}{c}\text { EC, мкС/см } \\
\mu \mathrm{S} / \mathrm{cm}\end{array}$} & \multirow[b]{2}{*}{$\begin{array}{c}\delta(\mathrm{EC}) \\
\%\end{array}$} & \multicolumn{2}{|c|}{$\begin{array}{c}\mathrm{Na}^{+}, \mathrm{M \Gamma} / \mathrm{дm}^{3} \\
\mathrm{mg} / \mathrm{dm}^{3}\end{array}$} & \multirow[b]{2}{*}{$\begin{array}{c}\delta\left(\mathrm{Na}^{+}\right), \\
\%\end{array}$} & \multicolumn{2}{|c|}{$\begin{array}{c}\mathrm{Cl}^{-}, \mathrm{Mг} / \text { дм }^{3} \\
\mathrm{mg} / \mathrm{dm}^{3}\end{array}$} & \multirow[b]{2}{*}{$\delta\left(\mathrm{Cl}^{-}\right), \%$} \\
\hline & & & $\begin{array}{l}\vec{\sim} \\
\ddot{\delta} \\
\infty \\
\infty \\
\infty\end{array}$ & $\begin{array}{l}\vec{\sim} \\
\stackrel{0}{0} \\
\stackrel{0}{0}\end{array}$ & & $\begin{array}{l}\vec{\sim} \\
\ddot{0} \\
\infty \\
\infty \\
\infty\end{array}$ & $\begin{array}{l}\vec{\sim} \\
\stackrel{0}{0} \\
\stackrel{0}{0}\end{array}$ & & 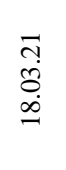 & $\begin{array}{l}\vec{\jmath} \\
\stackrel{0}{0} \\
\underline{0}\end{array}$ & & $\begin{array}{l}\vec{\sim} \\
\tilde{\sigma} \\
\infty \\
\infty\end{array}$ & $\begin{array}{l}\vec{\imath} \\
\stackrel{0}{0} \\
\stackrel{0}{0}\end{array}$ & \\
\hline & $\mathrm{T} / \mathrm{p}$ & $3,00-3,25$ & 8,19 & 8,26 & 0,9 & 129 & 122 & $-5,3$ & 5,0 & 3,7 & $-25,1$ & 3,0 & 4,6 & 54,9 \\
\hline & $\mathrm{T} / \mathrm{p}$ & $3,25-3,50$ & 8,09 & 8,26 & 2,1 & 171 & 101 & $-40,9$ & 3,7 & 1,6 & $-56,7$ & 5,4 & 2,9 & $-46,5$ \\
\hline & ут/wp & $3,50-3,75$ & 8,23 & 8,30 & 0,9 & 119 & 124 & 4,4 & 8,3 & 4,9 & $-41,0$ & 22,8 & 2,7 & $-88,2$ \\
\hline & ут/wp & $3,75-4,00$ & 8,23 & 8,30 & 0,9 & 119 & 124 & 4,4 & 8,3 & 4,9 & $-41,0$ & 22,8 & 2,7 & $-88,2$ \\
\hline & ут/wp & $4,00-4,25$ & 8,23 & 8,42 & 2,3 & 119 & 92 & $-22,9$ & 8,3 & 1,5 & $-82,3$ & 22,8 & 2,5 & $-89,2$ \\
\hline & Т (ч) $/ \mathrm{p}$ (b) & $4,25-4,50$ & 8,10 & 8,42 & 4,0 & 134 & 92 & $-31,6$ & 3,0 & 1,5 & $-50,8$ & 2,5 & 2,5 & $-2,4$ \\
\hline & OMO/OMS & $4,50-4,75$ & 8,16 & 8,41 & 3,1 & 129 & 81 & $-36,9$ & 2,7 & 2,1 & $-21,5$ & 2,4 & 1,1 & $-53,5$ \\
\hline & $\begin{array}{c}\text { Суглинок } \\
\text { Loam } \\
\end{array}$ & $4,75-5,00$ & 8,40 & 8,41 & 0,1 & 83 & 81 & $-2,2$ & 2,2 & 2,1 & $-1,9$ & 1,7 & 1,1 & $-33,3$ \\
\hline \multirow[t]{19}{*}{$\mathrm{H} 4$} & $\mathrm{~T} / \mathrm{p}$ & $0,00-0,25$ & 7,73 & 7,90 & 2,2 & 388 & 185 & $-52,4$ & 7,4 & 8,0 & 8,5 & 24,6 & 10,8 & $-56,1$ \\
\hline & $\mathrm{T} / \mathrm{p}$ & $0,25-0,50$ & 7,79 & 8,14 & 4,4 & 294 & 150 & $-49,1$ & 10,7 & 5,5 & $-48,3$ & 18,9 & 7,9 & $-58,2$ \\
\hline & $\mathrm{T} / \mathrm{p}$ & $0,50-0,75$ & 7,89 & 8,37 & 6,1 & 240 & 115 & $-52,3$ & 10,1 & 3,1 & $-69,6$ & 13,0 & 5,0 & $-61,5$ \\
\hline & $\mathrm{T} / \mathrm{p}$ & $0,75-1,00$ & 8,08 & 8,33 & 3,1 & 127 & 108 & $-15,2$ & 3,4 & 2,5 & $-26,5$ & 5,3 & 2,0 & $-63,2$ \\
\hline & $\mathrm{T} / \mathrm{p}$ & $1,00-1,25$ & 8,18 & 8,26 & 1,0 & 128 & 115 & $-10,5$ & 1,9 & 2,8 & 49,7 & 2,7 & 3,3 & 18,6 \\
\hline & $\mathrm{T} / \mathrm{p}$ & $1,25-1,50$ & 8,03 & 7,97 & $-0,7$ & 132 & 144 & 9,3 & 3,5 & 3,4 & $-1,4$ & 4,5 & 3,3 & $-27,3$ \\
\hline & $\mathrm{T} / \mathrm{p}$ & $1,50-1,75$ & 8,03 & 8,13 & 1,2 & 139 & 146 & 5,3 & 3,7 & 5,0 & 34,9 & 3,6 & 3,5 & $-4,7$ \\
\hline & $\mathrm{T} / \mathrm{p}$ & $1,75-2,00$ & 8,08 & 8,16 & 1,0 & 128 & 142 & 11,2 & 2,7 & 2,8 & 3,3 & 2,7 & 2,7 & 0,0 \\
\hline & $\mathrm{T} / \mathrm{p}$ & $2,00-2,25$ & 8,02 & 8,21 & 2,4 & 143 & 122 & $-14,6$ & 3,8 & 5,3 & 40,5 & 5,4 & 2,6 & $-52,0$ \\
\hline & $\mathrm{T} / \mathrm{p}$ & $2,25-2,50$ & 8,06 & 8,06 & 0,0 & 131 & 159 & 21,2 & 5,6 & 4,2 & $-25,5$ & 6,6 & 3,0 & $-54,3$ \\
\hline & $\mathrm{T} / \mathrm{p}$ & $2,50-2,75$ & 8,04 & 8,25 & 2,6 & 121 & 131 & 7,9 & 4,6 & 2,5 & $-45,1$ & 5,0 & 2,9 & $-42,3$ \\
\hline & $\mathrm{T} / \mathrm{p}$ & $2,75-3,00$ & 8,07 & 8,20 & 1,6 & 158 & 144 & $-8,7$ & 5,1 & 2,8 & $-44,6$ & 9,5 & 3,0 & $-68,8$ \\
\hline & $\mathrm{T} / \mathrm{p}$ & $3,00-3,25$ & 8,22 & 8,27 & 0,6 & 117 & 114 & $-2,9$ & 4,0 & 2,8 & $-30,6$ & 3,0 & 1,5 & $-50,0$ \\
\hline & $\mathrm{T} / \mathrm{p}$ & $3,25-3,50$ & 8,20 & 8,20 & 0,0 & 118 & 122 & 3,7 & 3,0 & 2,4 & $-20,2$ & 2,0 & 1,3 & $-31,6$ \\
\hline & $\mathrm{T} / \mathrm{p}$ & $3,50-3,75$ & 8,25 & 8,28 & 0,4 & 113 & 119 & 5,6 & 3,8 & 2,2 & $-42,3$ & 5,0 & 1,3 & $-74,4$ \\
\hline & $\mathrm{T} / \mathrm{p}$ & $3,75-4,00$ & 8,18 & 8,29 & 1,3 & 117 & 117 & $-0,1$ & 3,6 & 7,4 & 104,4 & 3,1 & 1,7 & $-46,5$ \\
\hline & T (ч)/p (b) & $4,00-4,25$ & 8,05 & 8,28 & 2,8 & 146 & 112 & $-23,3$ & 3,6 & 4,8 & 32,6 & 3,3 & 1,7 & $-49,1$ \\
\hline & $\mathrm{T} / \mathrm{p}$ & $4,25-4,50$ & 7,92 & 8,26 & 4,3 & 167 & 107 & $-35,8$ & 3,7 & 2,2 & $-41,6$ & 3,6 & 1,7 & $-53,1$ \\
\hline & $\mathrm{T} / \mathrm{p}$ & $4,50-4,75$ & 8,43 & 8,62 & 2,3 & 84 & 63 & $-24,9$ & 1,3 & 1,3 & $-0,8$ & 2,0 & 1,0 & $-51,5$ \\
\hline \multirow[t]{21}{*}{ H5 } & $\mathrm{T} / \mathrm{p}$ & $0,00-0,25$ & 7,89 & 7,85 & $-0,5$ & 280 & 164 & $-41,4$ & 18,8 & 8,9 & $-52,7$ & 21,0 & 7,4 & $-64,8$ \\
\hline & $\mathrm{T} / \mathrm{p}$ & $0,25-0,50$ & 7,94 & 7,85 & $-1,1$ & 323 & 164 & $-49,2$ & 11,5 & 8,9 & $-22,6$ & 8,9 & 7,4 & $-16,4$ \\
\hline & $\mathrm{T} / \mathrm{p}$ & $0,50-0,75$ & 8,13 & 8,16 & 0,4 & 139 & 147 & 5,7 & 6,7 & 5,3 & $-21,1$ & 3,7 & 4,7 & 27,0 \\
\hline & $\mathrm{T} / \mathrm{p}$ & $0,75-1,00$ & 8,21 & 8,22 & 0,1 & 125 & 119 & $-4,6$ & 5,8 & 3,2 & $-44,9$ & 4,5 & 2,5 & $-45,1$ \\
\hline & $\mathrm{T} / \mathrm{p}$ & $1,00-1,25$ & 8,23 & 8,25 & 0,2 & 120 & 119 & $-1,0$ & 5,7 & 2,8 & $-50,0$ & 5,7 & 2,0 & $-64,3$ \\
\hline & $\mathrm{T} / \mathrm{p}$ & $1,25-1,50$ & 8,23 & 8,44 & 2,6 & 117 & 89 & $-24,2$ & 4,5 & 2,7 & $-41,4$ & 4,0 & 2,2 & $-44,4$ \\
\hline & $\mathrm{T} / \mathrm{p}$ & $1,50-1,75$ & 8,16 & 8,36 & 2,5 & 128 & 89 & $-30,8$ & 5,0 & 2,6 & $-47,5$ & 3,1 & 2,0 & $-35,7$ \\
\hline & $\mathrm{T} / \mathrm{p}$ & $1,75-2,00$ & 8,23 & 8,31 & 1,0 & 107 & 89 & $-17,1$ & 4,5 & 2,0 & $-55,2$ & 3,3 & 2,2 & $-32,1$ \\
\hline & $\mathrm{T} / \mathrm{p}$ & $2,00-2,25$ & 8,23 & 8,29 & 0,7 & 120 & 103 & $-14,1$ & 4,0 & 2,8 & $-29,2$ & 3,2 & 1,5 & $-54,2$ \\
\hline & $\mathrm{T} / \mathrm{p}$ & $2,25-2,50$ & 8,20 & 8,20 & 0,0 & 121 & 116 & $-4,0$ & 4,4 & 2,5 & $-41,9$ & 5,6 & 2,1 & $-62,0$ \\
\hline & $\mathrm{T} / \mathrm{p}$ & $2,50-2,75$ & 8,14 & 8,25 & 1,4 & 139 & 120 & $-13,5$ & 4,5 & 3,2 & $-29,3$ & 3,6 & 2,2 & $-39,1$ \\
\hline & $T / p$ & $2,75-3,00$ & 8,30 & 8,17 & $-1,6$ & 130 & 129 & $-0,9$ & 3,9 & 2,6 & $-32,7$ & 2,7 & 2,0 & $-24,9$ \\
\hline & $\mathrm{T} / \mathrm{p}$ & $3,00-3,25$ & 8,17 & 8,16 & $-0,1$ & 143 & 120 & $-16,1$ & 4,9 & 2,8 & $-43,3$ & 4,1 & 1,8 & $-56,8$ \\
\hline & $\mathrm{T} / \mathrm{p}$ & $3,25-3,50$ & 8,17 & 8,16 & $-0,1$ & 122 & 131 & 7,5 & 3,7 & 2,8 & $-23,1$ & 2,5 & 1,4 & $-43,1$ \\
\hline & ут/wp & $3,50-3,75$ & 8,14 & 8,19 & 0,6 & 128 & 126 & $-2,0$ & 8,2 & 2,3 & $-72,2$ & 9,7 & 1,1 & $-88,4$ \\
\hline & $\mathrm{T} / \mathrm{p}$ & $3,75-4,00$ & 8,17 & 8,05 & $-1,5$ & 130 & 155 & 18,9 & 6,9 & 3,0 & $-56,4$ & 5,7 & 1,8 & $-68,7$ \\
\hline & $\mathrm{T} / \mathrm{p}$ & $4,00-4,25$ & 8,15 & 8,05 & $-1,2$ & 134 & 155 & 15,4 & 4,0 & 3,0 & $-26,0$ & 3,3 & 1,8 & $-45,8$ \\
\hline & T (ч)/p (b) & $4,25-4,50$ & 8,03 & 8,03 & 0,0 & 170 & 165 & $-3,1$ & 5,7 & 2,8 & $-50,1$ & 5,0 & 1,8 & $-64,5$ \\
\hline & T (ч)/p (b) & $4,50-4,75$ & 8,13 & 8,07 & $-0,7$ & 146 & 149 & 1,8 & 5,4 & 2,3 & $-56,6$ & 4,7 & 1,8 & $-61,9$ \\
\hline & T (ч)/p (b) & $4,75-5,00$ & 8,11 & 8,16 & 0,6 & 142 & 46 & $-67,8$ & 7,0 & 1,1 & $-84,4$ & 6,3 & 1,1 & $-83,1$ \\
\hline & $\mathrm{OMO} / \mathrm{OMS}$ & $5,00-5,25$ & 8,06 & 8,56 & 6,2 & 132 & 54 & $-59,3$ & 3,7 & 0,8 & $-78,0$ & 3,5 & 1,1 & $-68,3$ \\
\hline
\end{tabular}

Примечание: ЕС - удельная электропроводимость; грунт: $m$ - тор $\phi ; m$ (б) - торф белого цвета; $m$ (ч) - торф черного ивета; ут - переувлажненный торф; ОМО - органо-минеральные отложения.

Note: EC is the specific electric conductivity; ground: $p$ is the peat; $p(w)$ is the peat of white color; $p(b)$ is the peat of black color; wp is the waterlogged peat; OMS is the organo-mineral sediments.

Анализ ранее полученной информации и опубликованных материалов других авторов [10] позволяет сделать вывод о наличии линз пересыщенного водой торфа в разных частях Обского болота - как по территории, так и по глубине. Формирование линз, судя по минерализации болотных и подземных вод [27-31], связано с притоком напорных подземных вод из от- ложений палеогенового и, видимо, мелового возраста, а также грунтовых вод (из четвертичных отложений) и поверхностных вод с прилегающей к болоту территории. В зависимости от напора подземных вод, влагосодержания и фильтрационных свойств минеральных и торфяных грунтов эти воды перераспределяются в болотной среде, причем их влияние наиболее 
устойчиво в течение года вблизи от внешней границы болота. По мере удаления от границы роль случайных факторов возрастает, что, вероятно, и приводит к большей изменчивости физико-химических и геохимических показателей в скважинах Н4 и Н5.

Таким образом, повышенные концентрации $\mathrm{Na}^{+}$и $\mathrm{Cl}^{-}$в интервале глубин 1,50-2,0 м (в основном в интервале 1,50-1,75 м) в скважине Н3 можно объяснить как накоплением раствора $\mathrm{NaCl}$, выпущенного 19.03.21 г., так и смещением линзы переобводненного торфа ближе к поверхности болота. Для проверки этих гипотез в водных вытяжках из торфов были дополнительно определены концентрации $\mathrm{Ca}^{2+}$ в предположении, что их изменение синхронно с $\mathrm{Na}^{+}$и $\mathrm{Cl}^{-}$ может свидетельствовать, скорее, в пользу второй гипотезы. Это связано со следующим: 1) подземные воды палеогеновых отложений в этом районе по минерализации от пресных со средней и повышенной минерализацией до солоноватых, а по составу гидрокарбонатные кальциевые и гидрокарбонатные натриевые; 2) соотношение $\mathrm{Na}^{+}$и $\mathrm{Ca}^{2+}$, безусловно, может варьировать по мере изменения минерализации и ряда других причин, но увеличение $\mathrm{Na}^{+}$и $\mathrm{Cl}^{-}$вследствие притока подземных вод, тем не менее, должно сопровождаться и заметным ростом содержаний $\mathrm{Ca}^{2+}$. Однако сопоставление полученных материалов показало, что в скважине Н3 значимое увеличение концентраций $\mathrm{Ca}^{2+}$ в интервале глубин 1,50-1,75 м не прослеживается (рис. 4). С учетом этого более вероятно накопление $\mathrm{Na}^{+}$и $\mathrm{Cl}^{-}$в результате инфильтрации раствора $\mathrm{NaCl}$ на глубину до 2,0 м, причем в течение 211 суток концентрация раствора $\mathrm{NaCl}$ уменьшилась от 20 г/дм до содержаний $\mathrm{Na}^{+} 11,5$ мг/дм ${ }^{3}$ и $\mathrm{Cl}^{-} 22,4$ мг/дм ${ }^{3}$.

В водных вытяжках из торфов, отобранных в скважинах H1, H2, H4, Н5 (вершинах квадрата с центром в скважине Н3), статистически значимые изменения значений $\mathrm{pH}$, удельной электропроводности, концентраций $\mathrm{Na}^{+}$и $\mathrm{Cl}^{-}$, явно связанные с выпуском раствора $\mathrm{NaCl}$, а не с флуктуациями природных факторов, в целом не обнаружены (табл. 3, 4, рис. 5). Так, относительное увеличение концентраций $\mathrm{Na}^{+}$и $\mathrm{Cl}^{-}$ отмечено в интервалах глубин $0,50-0,75$ и 3,75-4,00 м в скважине $\mathrm{H} 1$, расположенной ниже по уклону от скважины Н3 (рис. 1). Подобные тенденции характерны и для скважины Н2, расположенной выше по уклону от скважины Н3, ближе к внешней границе болота, но не выявлены для скважины Н5 (ниже по уклону от Н3 на удалении от внешней границы болота). Таким образом, влияние выпуска раствора $\mathrm{NaCl}$ ограничено участком с площадью существенно меньше 1 га и глубиной торфяной залежи до 2,0 м.

В работе [32] было сделано предположение, что олиготрофное болото в условиях таежной зоны в Западной Сибири способно «справиться» в течение 3-5 лет с загрязнением в виде разового поступления нефтепродуктов до 16-17 т. Полученные авторами результаты в целом подтверждают этот вывод. Причем с учетом ранее полученных данных о влиянии сбросов хозяйственно-бытовых стоков в с. Мельниково [6-8] можно утверждать, что евтрофные долинные болота обладают не меньшей, по сравнению с олиготрофными водораздельными болотами, способностью к самоочищению.

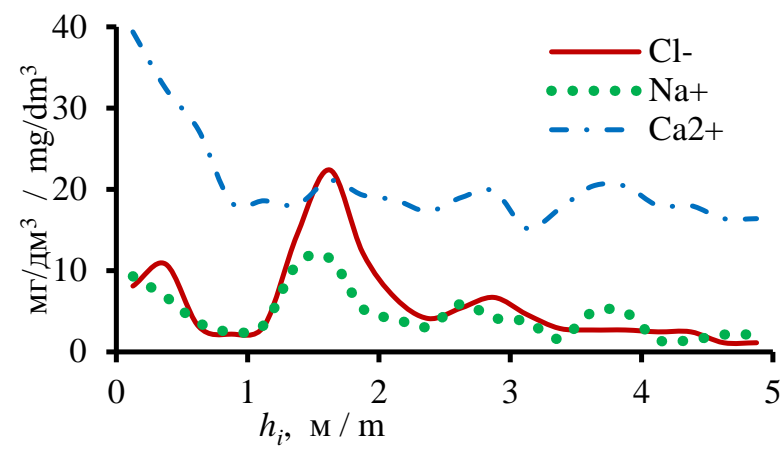

Puc. 4. Изменение концеентраций $\mathrm{Ca}^{2+}, \mathrm{Na}^{+}$и $\mathrm{Cl}^{-}$в водных вытяжках из торфов в скважине Н3 16 октября 2021 г.

Fig. 4. Change of $\mathrm{Ca}^{2+}, \mathrm{Na}^{+}$and $\mathrm{Cl}^{-}$concentration in water extracts from peats in borehole H3, 16.10.2021

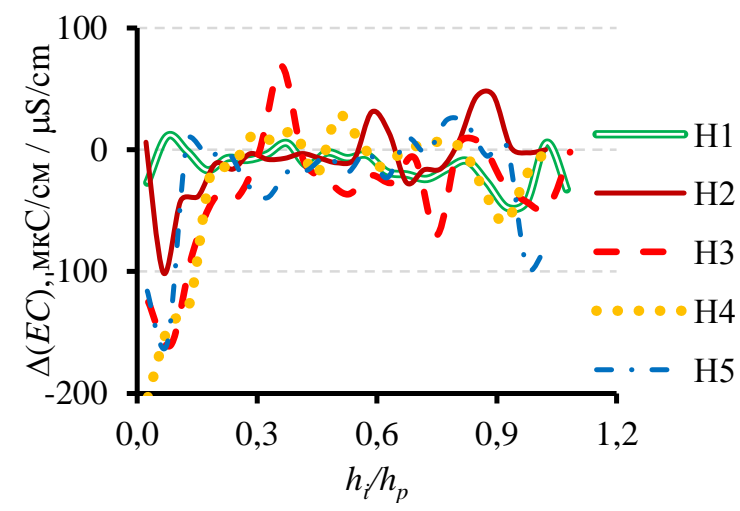

Pис. 5. Изменение удельной электропроводности водных вытяжек из торфов по скважинам H1-H5 с марта по октябрь $2021\left(\Delta(E C)=E C_{16.10 .21}-\right.$ $E C_{18.03 .21} ; E C_{\text {дата }}-$ удельная электропроводность на дату отбора пробы воды и проведения измерения)

Fig. 5. Change in specific electric conductivity of water extracts from peats on boreholes H1-H5 from March till October $2021\left(\Delta(E C)=E C_{16.10 .21}-\right.$ $E C_{18.03 .21} ; E C_{\text {дата }}$ is the specific electric conductivity for date of sampling)

Так, многолетний сброс хозяйственно-бытовых стоков в Обское болото у с. Мельниково (по крайней мере, с 1940-х гг.) привел к заметному увеличению значений ряда геохимических показателей болотных вод и торфов в верхней части торфяной залежи на участке, ограниченном в основном: вдоль р. Оби створом около 400 м к северу от выпуска стоков; по поперечному профилю речной долины - створом примерно в 500-700 м от внешней границы болота. Разовое же поступление в это болото относительно небольшого количества растворенных солей, как показало рассматриваемое исследование, оказывает на эколого-геохимическое состояние евтрофной болотной экосистемы еще меньшее влияние (на границе достоверного выявления). 


\section{Заключение}

Выпуск 50 л раствора $\mathrm{NaCl}$ с концентрацией 20 г/дм ${ }^{3}$ на поверхность евтрофного Обского болота 19 марта 2021 г. привел к формированию по состоянию на 16 октября 2021 г. непосредственно в этом месте (скважина Н3) относительно повышенных содержаний $\mathrm{Na}^{+}$и $\mathrm{Cl}^{-}$в деятельном горизонте торфяной залежи и в интервале глубин 1,50-2,00 (в основном в интервале $1,50-1,75$ м). Скважина Н3 расположена в центре квадрата со сторонами 100 м. В вершинах этого квадрата (то есть на удалении от скважины $\mathrm{H3}$ около 70 м) статистически значимые изменения значений $\mathrm{pH}$, удельной электропроводности $E C$, концентраций $\mathrm{Na}^{+}$и $\mathrm{Cl}^{-}$в болотных водах, явно связанные с выпуском раствора $\mathrm{NaCl}$ у скважины $\mathrm{H} 3$, не выявлены.

Вместе с тем установлено заметное влияние на эколого-геохимическое состояние евтрофного Обского болота притока подземных вод. Это влияние наиболее ощутимо и устойчиво в течение всего 2021 г по линии скважин $\mathrm{H} 1-\mathrm{H} 2$ на удалении 100 м от внешней границы Обского болота и наименее - по

\section{СПИСОК ЛИТЕРАТУРЫ}

1. Болотные системы Западной Сибири и их природоохранное значение / О.Л. Лисс, Л.И. Абрамова, Н.А. Аветов, Н.А. Березина, Л.И. Инишева, Т.В. Курнишкова, З.А. Слука, Т.Ю. Толпышева, Н.К. Шведчикова / под ред. В.Б. Куваева. - Тула: Гриф и К ${ }^{\circ}, 2001 .-584$ c.

2. Eurasian mires of the Southern Taiga Belt: modern features and response to Holocene palaeoclimate / T. Minayeva, W. Bleuten, A. Sirin, E.D. Lapshina // Wetlands and Natural Resource Management. Ecological Studies. V. 190 / Eds. J.T.A. Verhoeven, B. Beltman, R. Bobbink, D.F. Whigham. - Berlin: Heidelberg: Springer-Verlag, 2006. - P. 315-341.

3. Охрана окружающей среды в территориальном ЗападноСибирском комплексе / В.А. Шишов, В.Ю. Шеметов, В.И. Рябченко, В.П. Парфенов. - М.: ВНИИОЭНГ, 1988. - 50 с.

4. Ecosystem recovery and natural degradation of spilled crude oil in peat bog ecosystems of West Siberia / W. Bleuten, E. Lapshina W. Ivens, V. Shinkarenko, E. Wiersma // International Peat Journal. - 1999. - № 9. - P. 73-82.

5. Global wetlands: potential distribution, wetland loss, and status S. Hu, Zh. Niu, Y. Chen, L. Li, H. Zhang // Science of the Total Environment. - 2017. - V. 586. - P. 319-327. DOI: 10.1016/j.scitotenv.2017.02.001

6. Химический состав вод Обского болота (Западная Сибирь) и его пространственные изменения под влиянием сбросов загрязняющих вешеств / О.Г. Савичев, Н.В. Гусева, Е.А. Куприянов, А.А. Скороходова, К.В. Ахмед-Оглы // Известия Томского политехнического университета. - 2013 - Т. 323. - № 1. C. $168-172$.

7. Условия трансформации коммунально-бытовых сточных вод в болотных экосистемах (на примере Обского болота, Западная Сибирь) / И.С. Иванова, О.Г. Савичев, Е.А. Солдатова, Н.Г. Наливайко, Д.С. Корнеев, Н.В. Гусева, Н.А. Смирнова // Известия Томского политехнического университета. Инжиниринг георесурсов. - 2020. - Т. 331. - № 3. - С. 39-51. DOI $10.18799 / 24131830 / 2020 / 3 / 2530$.

8. Mineralogical and geochemical features of peat deposit of eutrophic the Obskoye fen in anthropogenous conditions (the Western Siberia) / O.G. Savichev, M.A. Rudmin, A.K. Mazurov, N.G. Nalivaiko, V.I. Sergienko, I.P. Semiletov // Doklady Earth Sciences. - 2020. - V. 492. - P. 1. - P. 320-322. DOI: 10.1134/S1028334X20050219.

9. Карта торфяных месторождений Западной Сибири. Масштаб 1:1000000: объяснительная записка / под ред. Р.Г. Матухина. Новосибирск: Изд-во СО РАН: Филиал «Гео», 2000. - 33 с.

10. Vegetation characteristics and eco-hydrological processes in a pristine mire in the Ob River valley (Western Siberia) / линии скважин $\mathrm{H} 4-\mathrm{H} 5$ на удалении 200 м от границы болота. Оно проявляется как непосредственно за счет поступления вод с минерализацией около 1 г/дм ${ }^{3}$ и повышенного содержания $\mathrm{Fe}^{2+}$, так и косвенно - путем изменения условий функционирования болотной экосистемы, следствием чего, вероятно, является неравномерное по территории и глубине распределение фильтрационных свойств и влагосодержания грунтов, концентраций химических элементов и соединений (например, содержания фосфатов и карбонатов, в свою очередь, оказывающих влияние на процессы растворения и осаждения).

В целом евтрофное Обское болото характеризуется высокой способностью к поддержанию устойчивого эколого-геохимического состояния. При этом необходимо отметить, что это состояние не соответствует установленным в Российской Федерации нормам качества природных вод уже на фоновых участках.

Работа выполнена при финансовой поддержке гранта РФФИ БРИКС Т № 18-55-80015.

A.M. Schipper, R. Zeefat, F. Tanneberger, J.P. van Zuidam, W. Hahne, S.A. Schep, S. Loos, W. Bleuten, H. Joosten, E.D. Lapshina, M.J. Wassen // Plant Ecology. - 2007. - V. 193. - P. 131-145. DOI: $10.1007 / \mathrm{s} 11258-006-9253-\mathrm{x}$.

11. Савичев О.Г., Ян Хэнь. Гидрогеологические и гидрологические условия функционирования Обского и Баксинского болот (юго-восток Западно-Сибирской равнины) // Известия Томского политехнического университета. Инжиниринг георесурсов. - 2021 - Т. 332. - № 4. - C. 43-56. DOI: 10.18799/24131830/2021/04/3147.

12. ГОСТ 17644-83. Торф. Методы отбора проб из залежи и обработки их для лабораторных испытаний. - М.: Изд-во стандартов, 1983. $-12 \mathrm{c}$.

13. Требования к производству и результатам многоцелевого геохимического картирования масштаба 1:200 000/ отв. ред. Э.К. Буренков. - М.: ИМГРЭ, 2002. - 92 с.

14. Weight W.D. Hydrogeology field manual. $2^{\text {nd }}$ ed. - USA: The McGraw-Hill Companies, Inc., 2008. - 751 p.

15. Manual on stream gauging. V. I. Fieldwork. WMO. № 1044. Geneva, Switzerland: World Meteorological Organization, 2010. $252 \mathrm{p}$.

16. Geochemical barriers in oligotrophic peat bog (Western Siberia) / O. Savichev, E. Soldatova, M. Rudmin, A. Mazurov // Applied Geochemistry. - 2020. - V. 113. - 104519. DOI: 10.1016/j.apgeochem.2019.104519.

17. Пособие по определению расчетных гидрологических характеристик / под ред. А.В. Рождественского, А.Г. Лобановой. Л.: Гидрометеоиздат, 1984. - 448 с.

18. Nash J.E., Sutcliffe J.V. River flow forecasting through conceptual models. P. I - A discussion of principles // Journal of Hydrology. 1970. - № 10 (3). - Р. 282-290.

19. Алёкин О.А. Основы гидрохимии. - Л.: Гидрометеорологическое изд-во, 1970. - 444 с

20. Guznyaeva M., Turov Yu. Features of the chemical composition impurities in natural waters of oil and gas producing territories // $19^{\text {th }}$ International multidisciplinary scientific geoconference SGEM 2019. Conference proceedings. Science and technologies in geology, exploration and mining. - Albena, 30.06-06.07.2019. Bulgaria, Sofia: СТЕФ92, 2019. - P. 185-192. DOI: 10.5593/sgem2019/3.1/S12.024.

21. Serebrennikova O.V., Selyanina S.B., Russkikh I.V., Strel'nikova E.B. Compositional features of fat-soluble organic compounds of the peat of the European north of Russia // AIP Conference Proceedings (American Institute of Physics Inc.). - 2020. - № 2310. P. 020297. DOI: 10.1063/5.0034436.

22. Identification of hydrocarbons in the waters of raised bogs in the southern taiga of Western Siberia / I.V. Russkikh, E.B. Strel'nikova, 
O.V. Serebrennikova, E.S. Voistinova, Y.A. Kharanzhevskaya // Geochemistry International. - 2020. - V. 58. - № 4. - P. 447-455. DOI: $10.1134 / \mathrm{S} 0016702920040072$

23. Ephraim J.H., Allard B. Metal ion binding by humic substances // Modelling in Aquatic Chemistry / Eds. I. Grenthe, I. Puigdomenech. - Paris, France: OECD, Nuclear Energy Agency, 1997. - P. 207-244.

24. Solubility, mobility, and bioaccumulation of trace elements: abiotic processes in the rhizosphere / B. Robinson, N. Bolan, S. Mahimairaja, B. Clothier // Trace elements in the environment: biogeochemistry, biotechnology, and bioremediation / Ed. by M.N.V. Prasad, Ravi Naidu, Kenneth S. Sajwan. - New York, USA: Taylor \& Francis Group, 2006. - P. 97-110.

25. Мотузова Н.В. Соединения микроэлементов в почвах. Системная организация, экологическое значение, мониторинг. М.: ЛИБРОКОМ, 2013. - $168 \mathrm{c.}$

26. Iron adsorption onto soil and aquatic bacteria: XAS structura study / A.G. González, O.S. Pokrovsky, F. Jiménez-Villacorta L.S. Shirokova, J.M. Santana-Casiano, M. González-Dávila, E.E. Emnova // Chemical Geology. - 2014. - № 372. - P. 32-45. DOI: 10.1016/j.chemgeo.2014.02.013.

27. Ермашова Н.А. Геохимия подземных вод зоны активного водобмена Томской области в связи с решением вопросов водо- снабжения и охраны: автореф. дис. ... канд. геол.-минерал. наук. - Томск, 1998. - 44 c.

28. Горохова И.В., Зятева О.Ф. Геохимия минеральных вод верхнемеловых отложений в с. Мельниково Томской области // Обской вестник. - 2001. - № 1. - С. 110-113.

29. Колоколова О.В. Геохимия подземных вод района Томского водозабора: автореф. дис. ... канд. геол.-минерал. наук. Томск, 2003. - $21 \mathrm{c}$

30. Shvartsev S.L. Geochemistry of fresh groundwater in the main landscape zones of the Earth // Geochemistry International. 2008. - V. 46. - № 13. - Р. 1285-1398.

31. Состояние геологической среды (недр) на территории Сибирского федерального округа в 2018 г. Информационный бюллетень / под ред. В.А. Льготина. - Томск: Филиал «Сибирский региональный центр ГМСН», ФГБУ «Гидроспецгеология», 2019. - Вып. 15. - 218 с.

32. Савичев О.Г., Гусева Н.В. Методология управления геохимическим балансом водосборов на территории Западной Сибири // Известия Томского политехнического университета. Инжиниринг георесурсов. - 2020. - Т. 331. - № 5. - C. 28-45. DOI $10.18799 / 24131830 / 2020 / 5 / 2634$

Поступила 11.12.2021 2.

\section{Информация об авторах}

Савичев О.Г., доктор географических наук, профессор отделения геологии Инженерной школы природных ресурсов Национального исследовательского Томского политехнического университета.

Гусева Н.В., доктор геолого-минералогических наук, заместитель директора по научно-образовательной деятельности Инженерной школы природных ресурсов, заведующая кафедрой - руководитель отделения геологии на правах кафедры Инженерной школы природных ресурсов Национального исследовательского Томского политехнического университета.

Хващевская A.A., кандидат геолого-минералогических наук, доцент Инженерной школы природных ресурсов Национального исследовательского Томского политехнического университета, заведующая проблемной научно-исследовательской лабораторией гидрогеохимии.

Иванов А.Ю., кандидат геолого-минералогических наук, доцент Инженерной школы природных ресурсов Национального исследовательского Томского политехнического университета, директор обособленного подразделения «Центр учебных геологических практик».

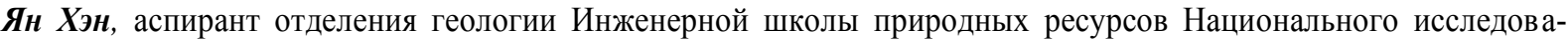
тельского Томского политехнического университета.

Чжсоу Дань, аспирант отделения геологии Инженерной школы природных ресурсов Национального исследовательского Томского политехнического университета. 
UDC 556.531.4:550.84.094

\title{
EXPERIMENT FOR ESTIMATING SELF-CLEANING OF THE OBSKOE FEN (WESTERN SIBERIA, TOMSK REGION)
}

\author{
Oleg G. Savichev ${ }^{1}$, \\ OSavichev@mail.ru \\ Natalya V. Guseva', \\ guseva24@yandex.ru
}

Albina A. Khvashchevskaya',
Garibova@yandex.ru

Andrey Yu. Ivanov ${ }^{1}$, IvanovAYu@tpu.ru

Yang Heng', 13698754927@163.com

Zhou Dan', 929177582@qq.com

1 National Research Tomsk Polytechnic University, 30, Lenin avenue, Tomsk, 634050, Russia.

Relevance. The flat area of Western Siberia is very swampy. Therefore economic activities are frequently carried out on swamps and the swampy grounds that defines the necessity of researches of the swamp environment self-cleaning for reduction in negative anthropogenous influence on an environment and optimization of economic activities.

The aim of the research is experimental studying of conditions of distribution in the swamp environment of polluting substances and selfcleaning of eutrophic fen.

Methods: field experiment, methods of definition of a chemical composition of peat and water, statistical methods.

Results and conclusions. Authors have drilled 5 boreholes and have selected samples of fen waters in active horizon of a peat deposit and peat through 0,25 $\mathrm{m}$ on the Obskoe fen (the south of Tomsk region) in area of settlement Nashchekovo on 18 March 2021. Four boreholes are located as tops of a square with the side $100 \mathrm{~m}$. The dump of 50 litres of $\mathrm{NaCl}$ solution with concentration of $20 \mathrm{~g} / \mathrm{dm}^{3}$ is executed in the middle of a square on a fen surface on 19.03.2021. Repeated drilling and sampling of marsh waters and peats are carried out on 16 October 2021. It is shown that during this period directly in a place of release of $\mathrm{NaCl}$ solution in an interval of depths of $1,50-2,00 \mathrm{~m}$ relative increased concentration of $\mathrm{Na}^{+}$(up to $11,5 \mathrm{mg} / \mathrm{dm}^{3}$ ) and $\mathrm{Cl}^{-}$(up to $22,4 \mathrm{mg} / \mathrm{dm}^{3}$ ) were generated. In other boreholes (on distance about $70 \mathrm{~m}$ from release) significant changes of values of $\mathrm{pH}$, specific electric conductivity $\mathrm{EC}, \mathrm{Na}^{+}$and $\mathrm{Cl}^{-}$concentration in fen waters and water extracts from the peats, associated with release of $\mathrm{NaCl}$ solution, are not revealed. It testifies to high ability of fen ecological system to self-cleaning.

\section{Key words:}

Self-cleaning, chemical composition, peat deposit, fen waters, Obskoe fen, Western Siberia.

The research was financially supported by the RFBR grant no. 18-55-80015.

\section{REFERENCES}

1. Liss O.L., Abramova L.I., Avetov N.A. Bolotnye sistemy Zapadnoy Sibiri i ikh prirodookhrannoe znachenie [Bog of Western Siberia and their conservation value]. Tula, Grif i K ${ }^{\circ}$ Publ., 2001. $584 \mathrm{p}$.

2. Minayeva T., Bleuten W., Sirin A., Lapshina E.D. Eurasian mires of the Southern Taiga Belt: modern features and response to Holocene palaeoclimate. Wetlands and Natural Resource Management. Ecological Studies. Vol. 190. Eds. J.T.A. Verhoeven, B. Beltman, R. Bobbink, D.F. Whigham. Berlin, Heidelberg, Springer-Verlag, 2006. pp. 315-341.

3. Shishov V.A., Shemetov V.Yu., Ryabchenko V.I., Parfenov V.P. Okhrana okruzhayushchey sredy $v$ territorialnom ZapadnoSibirskom komplekse [Environmental protection in the territorial West Siberian complex]. Moscow, VNIIOENG Publ., 1988. 50 p.

4. Bleuten W., Lapshina E., Ivens W., Shinkarenko V., Wiersma E. Ecosystem recovery and natural degradation of spilled crude oil in peat bog ecosystems of West Siberia. International Peat Journal, 1999, no. 9, pp. 73-82.
5. Hu S., Niu Zh., Chen Y., Li L., Zhang H. Global wetlands: potential distribution, wetland loss, and status. Science of the Total Environment, 2017, vol. 586, pp. 319-327. DOI: 10.1016/j.scitotenv.2017.02.001.

6. Savichev O.G., Guseva N.V., Kupriyanov E.A., Skorokhodova A.A., Akhmed-Ogly K.V. Chemical composition of the Ob Bog (West Siberia) and its spatial variations under the influence of the discharge of pollutants. Bulletin of the Tomsk Polytechnic University, 2013, vol. 323, no. 1, pp. 168-172. In Rus.

7. Ivanova I.S., Savichev O.G., Soldatova E.A., Nalivaiko N.G., Korneev D.S., Guseva N.V., Smirnova N.A. Conditions of transformation of municipal wastewater in bog ecosystems (on the example of Obskoe bog, Western Siberia). Bulletin of the Tomsk Polytechnic University. Geo Assets Engineering, 2020, vol. 331, no. 3, pp. 39-51. DOI: 10.18799/24131830/2020/3/2530.

8. Savichev O.G., Rudmin M.A., Mazurov A.K., Nalivaiko N.G., Sergienko V.I., Semiletov I.P. Mineralogical and geochemical features of peat deposit of eutrophic the Obskoye fen in anthropogenous conditions (the Western Siberia). Doklady Earth Sciences, 2020, vol. 492, P. 1, pp. 320-322. DOI: 10.1134/S1028334X20050219. 
9. Karta torfyanykh mestorozhdeniy Zapadnoy Sibiri. Masshtab 1:1000000: obyasnitelnaya zapiska [Map of peat deposits in Western Siberia. Scale 1:1000000: explanatory note]. Ed. by R.G. Matukhin. Novosibirsk, SB RAS Publ. house, Branch «Geo», 2000. 33 p.

10. Schipper A.M., Zeefat R., Tanneberger F., Van Zuidam J.P., Hahne W., Schep S.A., Loos S., Bleuten W., Joosten H., Lapshina E.D., Wassen M.J. Vegetation characteristics and ecohydrological processes in a pristine mire in the Ob River valley (Western Siberia). Plant Ecology, 2007, vol. 193, pp. 131-145. DOI: 10.1007/s11258-006-9253-X.

11. Savichev O.G., Yang Heng. Hydro-geological and hydrological conditions of functioning of the Obskoe and Baksinskoe fens (the southeast of the Western Siberian plain. Bulletin of the Tomsk Polytechnic University. Geo Assets Engineering, 2021, vol. 332, no. 4, pp. 43-56. DOI: 10.18799/24131830/2021/04/3147.

12. GOST 17644-83. Torf. Metody otbora prob iz zalezhi i obrabotki ikh dlya laboratornykh ispytany [SS 17644-83 Peat. Methods of sampling from deposit and preparation of samples for laboratory tests]. Moscow, Izdatelstvo standartov, 1983. $12 \mathrm{p}$.

13. Trebovaniya $k$ proizvodstvu $i$ rezultatam mnogotselevogo geokhimicheskogo kartirovaniya masshtaba 1:200000 [Requirements to production and results of multi-purpose geochemical mapping of scale 1:200000]. Ed. by E.K. Bkurenkov. Moscow, IMGRE, 2002. $92 \mathrm{p}$.

14. Weight W.D. Hydrogeology field manual. $2^{\text {nd }}$ ed. USA, The McGraw-Hill Companies, Inc., 2008. 751 p.

15. Manual on Stream Gauging. Vol. I. Fieldwork. WMO. No. 1044. Geneva, Switzerland, World Meteorological Organization, 2010. $252 \mathrm{p}$.

16. Savichev O., Soldatova E., Rudmin M., Mazurov A. Geochemical barriers in oligotrophic peat bog (Western Siberia). Applied Geochemistry, 2020, vol. 113, 104519. DOI: 10.1016/j.apgeochem.2019.104519.

17. Posobie po opredeleniyu raschetnykh gidrologicheskikh kharakteristik [The manual by definition of hydrological characteristics]. Eds. A.V. Rozhdestvensky, A.G. Lobanova. Leningrad, Gidrometeoizdat Publ., 1984. 448 p.

18. Nash J.E., Sutcliffe J.V. River flow forecasting through conceptua models. P. I - A discussion of principles. Journal of Hydrology, 1970, no. 10 (3), pp. 282-290.

19. Alekin O.A. Osnovy gidrokhimii [Bases of hydrochemistry]. Leningrad, Gidrometeoizdat Publ., 1970. 444 p.

20. Guznyaeva M., Turov Yu. Features of the chemical composition impurities in natural waters of oil and gas producing territories. $19^{\text {th }}$ International multidisciplinary scientific geoconference SGEM 2019. Conference proceedings. Science and technologies in geology, exploration and mining. Albena, 30.06-06.07.2019. Bulgaria, Sofia, CТЕФ92, 2019. pp. 185-192. DOI 10.5593/sgem2019/3.1/S12.024.

21. Serebrennikova O.V., Selyanina S.B., Russkikh I.V., Strel'nikova E.B Compositional features of fat-soluble organic compounds of the peat of the European north of Russia. AIP Conference Proceedings (American Institute of Physics Inc.), 2020, no. 2310, pp. 020297. DOI: $10.1063 / 5.0034436$
22. Russkikh I.V., Strel'nikova E.B., Serebrennikova O.V., Voistinova E.S Kharanzhevskaya Y.A. Identification of hydrocarbons in the waters of raised bogs in the southern taiga of Western Siberia. Geochemistry International, 2020, vol. 58, no. 4, pp. 447-455. DOI: 10.1134/S0016702920040072.

23. Ephraim J.H., Allard B. Metal ion binding by humic substances. Modelling in Aquatic Chemistry. Eds. I. Grenthe, I. Puigdomenech. Paris, France, OECD, Nuclear Energy Agency, 1997. pp. 207-244.

24. Robinson B., Bolan N., Mahimairaja S., Clothier B. Solubility, Mobility, and Bioaccumulation of Trace Elements: Abiotic Processes in the Rhizosphere. Trace elements in the environment: biogeochemistry, biotechnology, and bioremediation. Eds. M.N.V. Prasad, R. Naidu, K.S. Sajwan. New York, USA, Taylor \& Francis Group, 2006. pp. $97-110$.

25. Motuzova N.V. Soedineniya mikroelementov v pochvakh. Sistemnaya organizatsiya, ekologicheskoe znachenie, monitoring [Microelements in soils. System organization, ecological value, monitoring]. Moscow, LIBROCOM Publ., 2013. 168 p.

26. González A.G., Pokrovsky O.S., Jiménez-Villacorta F., Shirokova L.S., Santana-Casiano J.M., González-Dávila M., Emnova E.E. Iron adsorption onto soil and aquatic bacteria: XAS structural study. Chemical Geology, 2014, no. 372, pp. 32-45. DOI: 10.1016/j.chemgeo.2014.02.013.

27. Ermashova N.A. Geokhimiya podzemnykh vod zony aktivnogo vodobmena Tomskoy oblasti $v$ svyazi s resheniem voprosov vodosnabzheniya i okhrany. Avtoreferat Dis. Kand. nauk [Geochemistry of groundwater in the active water exchange zone of the Tomsk region in relation to solution of water supply and protection issues. Cand. Diss. Abstract]. Tomsk, 1998. 44 p.

28. Gorokhova I.V., Zyateva O.F. Geokhimiya mineralnykh vod verkhnemelovykh otlozheniy v s. Melnikovo Tomskoy oblasti [Geochemistry of mineral waters of the Upper Cretaceous deposits in the village. Melnikovo of the Tomsk region]. Obskoy vestnik, 2001, no. 1, pp. 110-113.

29. Kolokolova O.V. Geokhimiya podzemnykh vod rayona Tomskogo vodozabora. Avtoreferat Dis. Kand. nauk [Geochemistry of groundwater in the Tomsk water intake area. Cand. Diss. Abstract] Tomsk, 2003. $21 \mathrm{p}$.

30. Shvartsev S.L. Geochemistry of fresh groundwater in the main landscape zones of the Earth. Geochemistry International, 2008, vol. 46, no. 13, pp. 1285-1398.

31. Sostoyanie geologicheskoy sredy (nedr) na territorii Sibirskogo federalnogo okruga $v 2018 \mathrm{~g}$. Informatsionny byulleten [Condition of the geological environment (subsoil) in the territory of Siberian Federal District in 2018. Information bulletin]. Ed. by V.A. Lgotina. Tomsk, GMSN Siberian regional center branch, Gidrospetsgeologiya Publ., 2019. Iss. 15. 218 p.

32. Savichev O.G., Guseva N.V. Methodology of management of river basins geochemical balance in Western Siberia. Bulletin of the Tomsk Polytechnic University. Geo Assets Engineering, 2020, vol. 331, no. 5, pp. 28-45. DOI: 10.18799/24131830/2020/5/2634

Received: 11 December 2021.

\section{Information about the authors}

Oleg G. Savichev, Dr. Sc., professor, National Research Tomsk Polytechnic University.

Natalya V. Guseva, Dr. Sc., professor, head of the department, National Research Tomsk Polytechnic University.

Albina A. Khvashchevskaya, Cand. Sc., associate professor, head of the laboratory, National Research Tomsk Polytechnic University.

Andrey Yu. Ivanov, Cand. Sc., associate professor, director of the detached division «Center educational geological practice», National Research Tomsk Polytechnic University.

Yang Heng, postgraduate student, National Research Tomsk Polytechnic University.

Zhou Dan, postgraduate student, National Research Tomsk Polytechnic University. 